OPEN ACCESS

Edited by:

Maren Müller,

University of Barcelona, Spain

Reviewed by:

Vasileios Fotopoulos,

Cyprus University of Technology,

Cyprus

John Hancock

University of the West of England, UK

Jinpeng Gao,

Washington State University, USA

*Correspondence:

Jian Chen

jacksonchen206@gamil.com

${ }^{\dagger}$ These authors have contributed equally to this work.

Specialty section:

This article was submitted to

Plant Physiology,

a section of the journal

Frontiers in Plant Science

Received: 30 July 2016 Accepted: 07 February 2017

Published: 21 February 2017

Citation:

Lv W, Yang L, Xu C, Shi Z, Shao J, Xian M and Chen J (2017) Cadmium

Disrupts the Balance between Hydrogen Peroxide and Superoxide Radical by Regulating Endogenous Hydrogen Sulfide in the Root Tip of Brassica rapa.

Front. Plant Sci. 8:232.

doi: 10.3389/fpls.2017.00232

\section{Cadmium Disrupts the Balance between Hydrogen Peroxide and Superoxide Radical by Regulating Endogenous Hydrogen Sulfide in the Root Tip of Brassica rapa}

\author{
Wenjing Lv $v^{1,2,3 \dagger}$, Lifei Yang ${ }^{2 t}$, Cunfa Xu ${ }^{4}$, Zhiqi Shi ${ }^{1,3}$, Jinsong Shao ${ }^{5}$, Ming Xian ${ }^{6}$ and \\ Jian Chen ${ }^{1,3 *}$
}

${ }^{1}$ Institute of Food Quality and Safety, Jiangsu Academy of Agricultural Sciences, Nanjing, China, ${ }^{2}$ College of Horticulture, Nanjing Agricultural University, Nanjing, China, ${ }^{3}$ Key Lab of Food Quality and Safety of Jiangsu Province - State Key Laboratory Breeding Base, Jiangsu Provincial Department of Agriculture and Forestry, Nanjing, China, ${ }^{4}$ Central Laboratory, Jiangsu Academy of Agricultural Science, Nanjing, China, ${ }^{5}$ Agricultural Products Quality and Safety Superivision, Inspection, and Testing Center, Ministry of Agriculture, Nanjing, China, ${ }^{6}$ Department of Chemistry, Washington State University, Pullman, WA, USA

$\mathrm{Cd}$ (cadmium) stress always alters the homeostasis of ROS (reactive oxygen species) including $\mathrm{H}_{2} \mathrm{O}_{2}$ (hydrogen sulfide) and $\mathrm{O}_{2}^{\bullet-}$ (superoxide radical), leading to the oxidative injury and growth inhibition in plants. In addition to triggering oxidative injury, ROS has been suggested as important regulators modulating root elongation. However, whether and how Cd stress induces the inhibition of root elongation by differentially regulating endogenous $\mathrm{H}_{2} \mathrm{O}_{2}$ and $\mathrm{O}_{2}^{\bullet-}$, rather than by inducing oxidative injury, remains elusive. To address these gaps, histochemical, physiological, and biochemical approaches were applied to investigate the mechanism for $\mathrm{Cd}$ to fine-tune the balance between $\mathrm{H}_{2} \mathrm{O}_{2}$ and $\mathrm{O}_{2}^{\bullet-}$ in the root tip of Brassica rapa. Treatment with $\mathrm{Cd}$ at 4 and $16 \mu \mathrm{M}$ significantly inhibited root elongation, while only $16 \mu \mathrm{M}$ but not $4 \mu \mathrm{M}$ of $\mathrm{Cd}$ induced oxidative injury and cell death in root tip. Fluorescent and pharmaceutical tests suggested that $\mathrm{H}_{2} \mathrm{O}_{2}$ and $\mathrm{O}_{2}^{\bullet-}$ played negative and positive roles, respectively, in the regulation of root elongation in the presence of $\mathrm{Cd}(4 \mu \mathrm{M})$ or not. Treatment with $\mathrm{Cd}$ at $4 \mu \mathrm{M}$ led to the increase in $\mathrm{H}_{2} \mathrm{O}_{2}$ and the decrease in $\mathrm{O}_{2}^{\bullet-}$ in root tip, which may be attributed to the up-regulation of Br_UPB1s and the down-regulation of their predicted targets (four peroxidase genes). Cd at $4 \mu \mathrm{M}$ resulted in the increase in endogenous $\mathrm{H}_{2} \mathrm{~S}$ in root tip by inducing the up-regulation of $\angle C D s$ and $D C D$ s. Treatment with $\mathrm{H}_{2} \mathrm{~S}$ biosynthesis inhibitor or $\mathrm{H}_{2} \mathrm{~S}$ scavenger significantly blocked $\mathrm{Cd}(4 \mu \mathrm{M})$-induced increase in endogenous $\mathrm{H}_{2} \mathrm{~S}$ level, coinciding with the recovery of root elongation, the altered balance between $\mathrm{H}_{2} \mathrm{O}_{2}$ and $\mathrm{O}_{2}^{\bullet-}$, and the expression of $\mathrm{Br}_{-}$UPB1s and two peroxidase genes. Taken together, it can be proposed that endogenous $\mathrm{H}_{2} \mathrm{~S}$ mediated the phytotoxicity of $\mathrm{Cd}$ at low concentration by regulating $\mathrm{Br} \_$UPB1s-modulated balance between $\mathrm{H}_{2} \mathrm{O}_{2}$ and $\mathrm{O}_{2}^{\bullet-}$ in root tip. Such findings shed new light on the regulatory role of endogenous $\mathrm{H}_{2} \mathrm{~S}$ in plant adaptions to Cd stress.

Keywords: cadmium, hydrogen sulfide, hydrogen peroxide, superoxide radical, root tip, Brassica rapa 


\section{INTRODUCTION}

Reactive oxygen species (ROS), a set of active forms of molecular oxygen $\left(\mathrm{O}_{2}\right)$ occurred in plant cells, comprise both free radical (e.g., $\mathrm{O}_{2}^{\bullet-}$, superoxide radical; $\mathrm{OH}$, hydroxyl radical) and nonradical forms (e.g., $\mathrm{H}_{2} \mathrm{O}_{2}$, hydrogen peroxide; ${ }^{1} \mathrm{O}_{2}$, singlet oxygen) (Gill and Tuteja, 2010). ROS accumulation can be frequently induced by environmental stimuli, which further results in oxidative injury in plants. However, ROS can act as second messengers in the regulation of plant intrinsic physiology and development under both stress and normal environmental conditions (Apel and Hirt, 2004). For instance, ROS has been suggested as one of the key workers for the regulation of plant root development. In the primary root of Arabidopsis, $\mathrm{O}_{2}^{\bullet-}$ located in the elongation zone (EZ) positively regulates root elongation, while $\mathrm{H}_{2} \mathrm{O}_{2}$ located in the differentiation zone (DZ) negatively regulates root elongation (Dunand et al., 2007). Additionally, both $\mathrm{H}_{2} \mathrm{O}_{2}$ and $\mathrm{O}_{2}^{\bullet-}$ are indispensable for the emergence of lateral root in Arabidopsis (Manzano et al., 2014). ROS functions as core modulator of sophisticated network of signaling pathways in plants, but the regulation of the exact nature of ROS-mediated signaling network remains largely obscured (Bhattacharjee, 2012). It has been evidenced that a basic helix-loop-helix transcription factor UPBEAT1 (UPB1) is an important regulator of ROS signaling during root development. UPB1 can directly suppress the expression of several peroxidases (Per39, Per40, and Per57) that modulate the balance between $\mathrm{H}_{2} \mathrm{O}_{2}$ and $\mathrm{O}_{2}^{\bullet-}$ (Tsukagoshi et al., 2010). The alteration of ROS balance resulted from the stimulation of UPB1 activity accelerates the onset of cell differentiation, leading to the inhibition of root elongation (Tsukagoshi et al., 2010). The reduced lateral root number was also found in both UPB1-overexpressing plant and per57 mutant, suggesting that UPB1-mediated ROS signaling is also important to control lateral root growth (Manzano et al., 2014). Nevertheless, UPB1/peroxidase-mediated ROS signaling acts independently of auxin signaling that is a typical regulator of root development (Tsukagoshi et al., 2010; Manzano et al., 2014).

Cadmium (Cd) contamination has been drawing great attention worldwide because large amounts of $\mathrm{Cd}$ have been released into the ecosystem due to both natural and anthropogenic activities (Satarug et al., 2010). Cd-induced phytotoxicity has been closely linked to the over-generation of ROS, leading to oxidative injury, lipid peroxidation, cell death, and growth stunt (DalCorso et al., 2010; Lin and Aarts, 2012; Andresen and Küpper, 2013). In general, excessive Cd at toxic dosage induces remarkable increases in both $\mathrm{H}_{2} \mathrm{O}_{2}$ and $\mathrm{O}_{2}^{\bullet-}$ in plants (Xu et al., 2012; Pérez-Chaca et al., 2014). $\mathrm{O}_{2}^{\bullet-}$ induced by $\mathrm{Cd}$ is mainly originated from NADPH oxidase (Jakubowska et al., 2015), while $\mathrm{H}_{2} \mathrm{O}_{2}$ is produced by the univalent reduction of $\mathrm{O}_{2}^{\bullet-}$ (Gill and Tuteja, 2010). In Cd-treated plants, ROS-mediated oxidative stress can be regulated by several factors, such as nitric oxide (NO) (Rodríguez-Serrano et al., 2009; Pérez-Chaca et al., 2014), $\mathrm{Ca}^{2+}$ (Rodríguez-Serrano et al., 2009), an oxidative stress-related Abc1-like protein (AtOAS1) (Jasinski et al., 2008), etc. In some cases, $\mathrm{H}_{2} \mathrm{O}_{2}$ and $\mathrm{O}_{2}^{\bullet-}$ can be differentially regulated by $\mathrm{Cd}$ stress. For instance, $\mathrm{Cd}$ induces two waves of ROS in the roots of Glycine max, which the maximum accumulation of $\mathrm{H}_{2} \mathrm{O}_{2}$ appears faster than that of $\mathrm{O}_{2}^{\bullet-}$ (Pérez-Chaca et al., 2014). In the roots of G. max and Cucumis sativus, $\mathrm{Cd}$ stimulates $\mathrm{H}_{2} \mathrm{O}_{2}$ production whereas it inhibits $\mathrm{O}_{2}^{\bullet-}$ production (Heyno et al., 2008). However, whether and how ROS act as signaling molecule rather than a trigger of oxidative stress to regulate root growth under $\mathrm{Cd}$ exposure remains obscured.

Hydrogen sulfide $\left(\mathrm{H}_{2} \mathrm{~S}\right)$ acting as an important signaling molecule in mammals has been highly appreciated for its clinical relevance (Wang, 2010; Kimura, 2011; Kimura et al., 2012; Vandiver and Snyder, 2012). The emerging role of $\mathrm{H}_{2} \mathrm{~S}$ in the modulation of various plant physiological pathways has been revealing, which is involved in the regulation of stomatal closure, phototosynthesis, seed germination, flower senescence, root development, and responses to abiotic stress, etc (GarcíaMata and Lamattina, 2013; Lisjak et al., 2013; Fotopoulos et al., 2015; Jia et al., 2015). $\mathrm{H}_{2} \mathrm{~S}$ can be produced by $\mathrm{L}_{\text {-cysteine }}$ desulfhydrase (LCD, EC4.4.1.1) and D-cysteine desulfhydrase (DCD, EC4.4.1.15) in plants (Papenbrock et al., 2007). Large amounts of reports suggest that exogenous application of $\mathrm{H}_{2} \mathrm{~S}$ can protect plants from metal toxicity by inhibiting the overgeneration of $\mathrm{H}_{2} \mathrm{O}_{2}$ or $\mathrm{O}_{2}^{\bullet-}$ (Zhang et al., 2008, 2010a,b; Chen et al., 2013; Bharwana et al., 2014; Shi et al., 2014). In our previous study, the endogenous $\mathrm{H}_{2} \mathrm{~S}$ detected selectively by a specific fluorescent probe Washington Stat Probe 1 (WSP-1) is essential for root growth under selenium stress by scavenging the over-generated total ROS and $\mathrm{O}_{2}^{\bullet-}$ (Chen et al., 2014). $\mathrm{H}_{2} \mathrm{~S}$ has been suggested to promote root organogenesis while $\mathrm{H}_{2} \mathrm{O}_{2}$ and $\mathrm{O}_{2}^{\bullet-}$ play vital role in the regulation of root growth (Zhang et al., 2009; Tsukagoshi et al., 2010). The antioxidant roles of $\mathrm{H}_{2} \mathrm{~S}$ in scavenging ROS have been highlighted in both plants and mammals (Ju et al., 2013; Hancock and Whiteman, 2014). Nevertheless, whether and how endogenous $\mathrm{H}_{2} \mathrm{~S}$ differentially fine-tunes the balance between $\mathrm{H}_{2} \mathrm{O}_{2}$ and $\mathrm{O}_{2}^{\bullet-}$ in vivo remains unclear.

In this work, we investigated the possible link between $\mathrm{H}_{2} \mathrm{~S}$ and ROS signaling in the regulation of root elongation under $\mathrm{Cd}$ exposure. First, we found a disturbance of the balance between $\mathrm{H}_{2} \mathrm{O}_{2}$ and $\mathrm{O}_{2}^{\bullet-}$ without any oxidative injury in root treated with $\mathrm{Cd}$ at a specific concentration. The involvement of the endogenous $\mathrm{H}_{2} \mathrm{~S}$ in the regulation of the above process was further elucidated. To get deeper insights into the link between of $\mathrm{H}_{2} \mathrm{~S}$ and ROS signaling, the expression of UPB1 and its possible targets were studied under the application of $\mathrm{H}_{2} \mathrm{~S}$-synthesizing inhibitor or $\mathrm{H}_{2} \mathrm{~S}$ scavenger in root in the presence of $\mathrm{Cd}$. Finally, the possible mechanisms driving these physiological processes, and their significance, were discussed.

\section{MATERIALS AND METHODS}

\section{Plant Culture, Treatment, and Chemicals}

Seeds of B. rapa (LvLing) seeds were surface-sterilized with 1\% $\mathrm{NaClO}$ for $10 \mathrm{~min}$ followed by washing with distilled water. Seeds were germinated for 1 day in the dark on the floating plastic nets. Then the selected identical seedlings with radicles $0.5 \mathrm{~cm}$ were 
transferred to another Petri dish containing various treatment solutions in a chamber with a photosynthetic active radiation of $200 \mu \mathrm{mol} / \mathrm{m}^{2} / \mathrm{s}$, a photoperiod of $12 \mathrm{~h}$, and the temperature at $25 \pm 1^{\circ} \mathrm{C}$.

Seedling roots were exposed to $\mathrm{CdCl}_{2}$ (cadmium chloride) with different concentrations $(0-32 \mu \mathrm{M})$ for various treatment time (0-72 h). PAG (DL-propargylglycine) (0.05-0.2 mM) and HT (hypotaurine) (0.1-0.4 mM) were used as $\mathrm{H}_{2} \mathrm{~S}$ biosynthesis inhibitor and $\mathrm{H}_{2} \mathrm{~S}$ scavenger, respectively (Chen et al., 2014). DPI (diphenylene iodonium) and KI (potassium iodide) were used as NADPH oxidase inhibitor and $\mathrm{H}_{2} \mathrm{O}_{2}$ scavenger, respectively (Tsukagoshi et al., 2010). The treatment solution is composed of different chemicals mentioned above alone or their combinations according to the experimental design. After treatments, the roots were washed with distilled water for physiological, histochemical, and biochemical analysis.

\section{Histochemical Analysis}

The intracellular $\mathrm{H}_{2} \mathrm{~S}$ was visualized using specific fluorescent probe WSP-1 [3'-methoxy-3-oxo-3H-spiro[isobenzofuran-1,9' xanthen]-6'-yl 2-(pyridin-2-yldisulfanyl) benzoate] in situ according to our previous method (Li et al., 2014). The roots of seedlings after treatments were incubated at $20 \mathrm{mM}$ Hepes$\mathrm{NaOH}$ ( $\mathrm{pH}$ 7.5) buffer solution containing $20 \mu \mathrm{M}$ of WSP-1 at $25^{\circ} \mathrm{C}$ for $40 \mathrm{~min}$. Then the roots were washed with distilled water three times and were visualized immediately by a fluorescence microscope with a 465/515 $\mathrm{nm}$ and an excitation/emission filter set (ECLIPSE, TE2000-S, Nikon). The relative fluorescent density of the fluorescent images was analyzed using Image-Pro Plus 6.0 (Media Cybernetics, Inc.).

Intracellular $\mathrm{O}_{2}^{\bullet-}$ was visualized in situ using specific fluorescent probe DHE (dihydroethidium) in situ described by Yamamoto et al. (2002). The roots of seedlings after treatment were incubated in $15 \mu \mathrm{M}$ of $\mathrm{DHE}$ at $25^{\circ} \mathrm{C}$ for $15 \mathrm{~min}$. Then the roots were rinsed with distilled water for three times and were visualized (excitation $535 \mathrm{~nm}$ and emission $610 \mathrm{~nm}$ ) by a fluorescence microscope (ECLIPSE, TE2000-S, Nikon). The relative fluorescent density of the fluorescent images was analyzed using Image-Pro Plus 6.0 (Media Cybernetics, Inc.).

Intracellular $\mathrm{H}_{2} \mathrm{O}_{2}$ was visualized in situ using specific fluorescent probe HPF ( $3^{\prime}$-(p-hydroxyphenyl) fluorescein) in situ described by Dunand and Crevecoeur (Dunand et al., 2007). The roots of seedlings after treatment were incubated in $5 \mu \mathrm{M}$ of $\mathrm{HPF}$ at $25^{\circ} \mathrm{C}$ for $15 \mathrm{~min}$. Then the roots were rinsed with distilled water for three times and were visualized (excitation $490 \mathrm{~nm}$ and emission $515 \mathrm{~nm}$ ) by a fluorescence microscope (ECLIPSE, TE2000-S, Nikon). The relative fluorescent density of the fluorescent images was analyzed using Image-Pro Plus 6.0 (Media Cybernetics, Inc.).

Histochemical detection of lipid peroxidation was achieved by using Schiff's regent as described by Wang and Yang (2005). The roots of seedlings after treatment were incubated in Schiff's regent for $20 \mathrm{~min}$. Then the stained roots were rinsed with a solution containing $0.5 \%(\mathrm{w} / \mathrm{v}) \mathrm{K}_{2} \mathrm{~S}_{2} \mathrm{O}_{5}$ (prepared in $0.05 \mathrm{M}$ of $\mathrm{HCl}$ ) until the root color became light red. After that, the roots were imaged by using a stereoscopic microscope (SteREO Discovery.V8, ZEISS).
Histochemical detection of loss of plasma membrane integrity was performed by using Evans blue as described by Yamamoto et al. (2001). The roots of seedlings after treatment were incubated in Evans blue solution $(0.025 \%, \mathrm{w} / \mathrm{v})$ for $20 \mathrm{~min}$. After that, the roots were rinsed with distilled water for three times followed by imaging with a stereoscopic microscope (SteREO Discovery.V8, ZEISS).

Histochemical detection of cell death was performed by using Trypan blue (Duan et al., 2010). The roots of seedlings after treatment were incubated in Trypan $10 \mathrm{mg} / \mathrm{mL}$ of blue solution for $20 \mathrm{~min}$. After that, the roots were rinsed with distilled water for three times followed by imaging with a stereoscopic microscope (SteREO Discovery.V8, ZEISS).

\section{Analysis of Transcripts}

Total RNA was extracted from root tip using Trizol (Invitrogen) according to the manufacturer's instructions. The possible genomic DNA was removed from extracted RNA samples by using Recombinant DNase I (RNase-free) (TaKaRa Bio Inc, China). Reverse transcription was performed at $42^{\circ} \mathrm{C}$ in $25 \mu \mathrm{l}$ reaction mixture including $3 \mu \mathrm{g}$ of RNA, $0.5 \mu \mathrm{g}$ of oligo (dT) primers, $12.5 \mathrm{nmol}$ of dNTPs, 20 units of RANase inhibitor and 200 units of M-MLV. The first cDNA was used as a template for polymerase chain amplification and to analyze the transcripts of genes by using real-time quantitative reverse transcriptionpolymerase chain reaction (qRT-PCR) (Applied Biosystems 7500 Fast Real-Time PCR System, LifeTechnologies ${ }^{\mathrm{TM}}$ ). with SYBR Premix Ex Taq ${ }^{\mathrm{TM}}$ (TaKaRa Bio Inc, China) according to the manufacturer's instructions. The qPCR procedure was as follows: initial denaturation at $95^{\circ} \mathrm{C}$ for $30 \mathrm{~s}$, followed by 40 cycles of $95^{\circ} \mathrm{C}$ for $5 \mathrm{~s}, 60^{\circ} \mathrm{C}$ for $30 \mathrm{~s}$, and $72^{\circ} \mathrm{C}$ for $30 \mathrm{~s}$. Data were collected and analyzed by using ABI 7500 software (v. 2.0.6, Applied Biosystems) based on $2^{-\Delta \Delta \mathrm{CT}}$ threshold cycle method (Livak and Schmittgen, 2001). The relative abundance of Actin was determined and used as the internal standard to normalize the data. The expression levels of corresponding genes are presented as values relative to the control samples under the indicated conditions. The primers designed for the amplification of the genes are listed in Supplementary Table 1.

\section{Cluster analysis}

Hierarchical cluster analysis for different parameters was performed by using Cluster $3.0^{1}$. The generated tree figures were displayed by using Java Treeview ${ }^{2}$ (de Hoon et al., 2004; Shi et al., 2014).

\section{Statistical analysis}

Each result was presented as the mean \pm standard deviation (SD) of at least three replicated measurement. The significant differences between treatments were statistically evaluated by SD and one-way analysis of variance (ANOVA) using SPSS 2.0. The data between two specific different treatments were compared statistically by ANOVA, followed by $F$-test if the ANOVA result is significant at $P<0.05$. For multiple comparison analysis,

\footnotetext{
${ }^{1}$ http://bonsai.hgc.jp/ mdehoon/software/cluster/

${ }^{2}$ https://sourceforge.net/projects/jtreeview/
} 
least significant difference test (LSD) was performed on all data following ANOVA tests to test for significant $(P<0.05)$ differences among different treatments.

\section{RESULTS}

\section{Cd at Specific Concentration Inhibited Root Growth Without Inducing Oxidative Injury and Cell Death}

In order to determine the effect of $\mathrm{Cd}$ exposure on root elongation, the roots of $B$. rapa were exposed to $\mathrm{CdCl}_{2}$ $(2-32 \mu \mathrm{M})$ for $72 \mathrm{~h}$. $\mathrm{CdCl}_{2}$ at $4-32 \mu \mathrm{M}$ significantly inhibited root growth in a dose-dependent manner (Supplementary Figure 1A). Root elongation significantly decreased by 23 and $53 \%$ at 4 and $16 \mu \mathrm{M}$ Cd levels, respectively, as compared to the control (Figure 1A). Cd stress always induces oxidative injury, leading to cell death in plants (Andresen and Küpper, 2013). Membrane

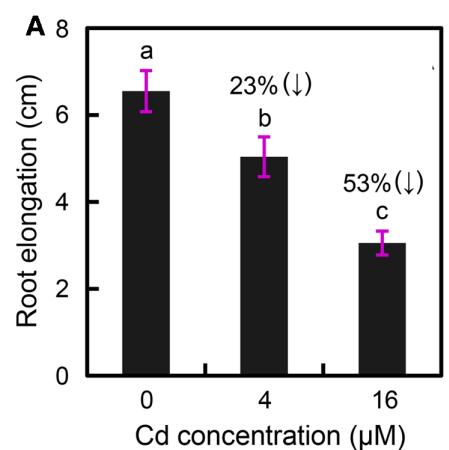

B

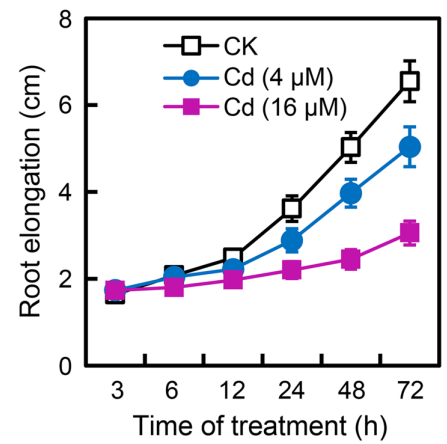

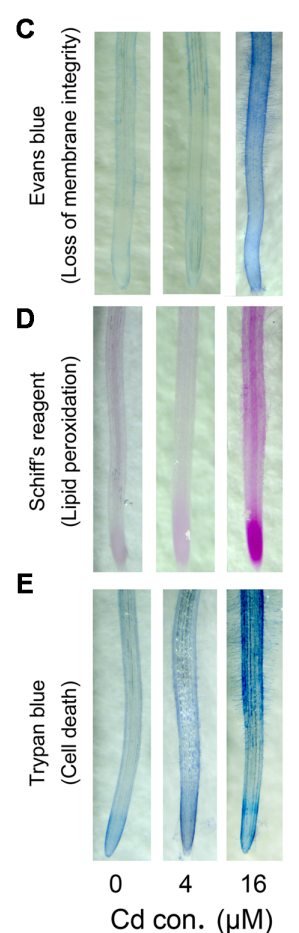

FIGURE 1 | Effect of Cadmium (Cd) stress on the root elongation and physiological changes in the root tip of Brassica rapa. (A) The root elongation was obtained when the roots of seedlings were exposed to 0,4 , and $16 \mu \mathrm{M}$ of $\mathrm{CdCl}_{2}$ (cadmium chloride) for $72 \mathrm{~h}$. The numbers in the top of columns indicate the inhibitory percentage of the treatments as compared to the control. The mean values of five replicates followed by different letters indicate significance of difference between the treatments $[P<0.05$, analysis of variance (ANOVA), least significant difference test (LSD)]. (B) The roots of seedlings were exposed to 0,4 , and $16 \mu \mathrm{M}$ of $\mathrm{CdCl}_{2}$. The average root elongation was obtained from five replicates at $3,6,12,24,48$, and $72 \mathrm{~h}$, respectively. (C-E) The root elongation was obtained when the roots of seedlings were exposed to 0 (control), 4 , and $16 \mu \mathrm{M}$ of $\mathrm{CdCl}_{2}$ for $72 \mathrm{~h}$. Then the roots were histochemically stained with Evans blue (C), Shiff's reagent (D), and trypan blue $(\mathbf{E})$, respectively, for imaging. lipid peroxidation, indicated by MDA (malondiadehyde) content, is the typical consequence of $\mathrm{Cd}$-induced oxidative injury. $\mathrm{Cd}$ at high concentrations $(8-32 \mu \mathrm{M})$, but not low concentrations $(2-4 \mu \mathrm{M})$, resulted in remarkable increase in MDA content in root as compared to control (Supplementary Figure 1B). Thus,

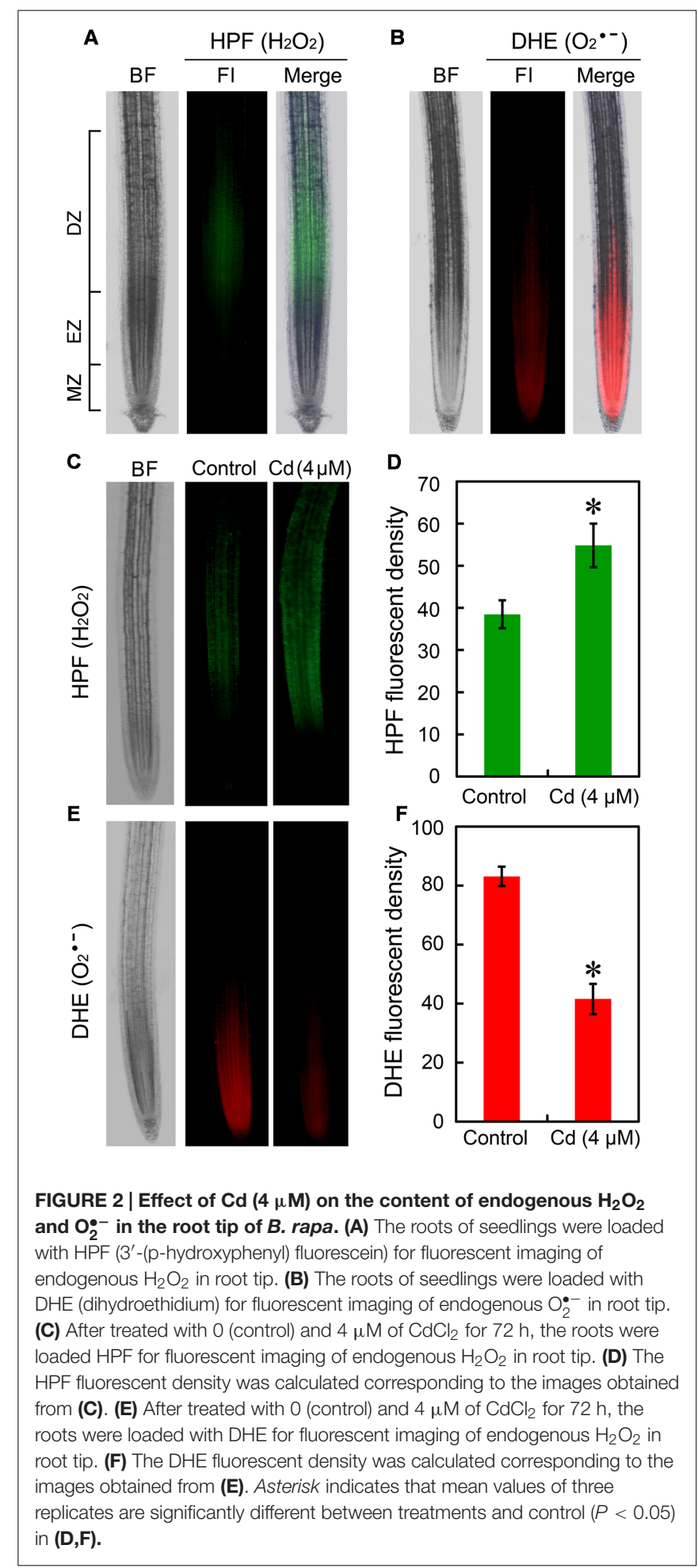


$\mathrm{Cd}$ at 4 and $16 \mu \mathrm{M}$ were considered to induce slight and relatively severe stress in root, respectively. In a time-course experiment, exposure of $\mathrm{Cd}$ at $16 \mu \mathrm{M}$ for only $6 \mathrm{~h}$ began to significantly inhibit root elongation, while root elongation treated with $\mathrm{Cd}$ at $4 \mu \mathrm{M}$ began to decrease remarkably after $24 \mathrm{~h}$ (Figure 1B). The peroxidation of membrane lipids and the loss of plasma membrane integrity were tested in vivo using histochemical staining with Shiff's reagent and Evans blue, respectively. Root tips treated with $4 \mu \mathrm{M}$ of $\mathrm{Cd}$ and the control group had only slight staining. Nevertheless, root tips treated with $\mathrm{Cd}$ at $16 \mu \mathrm{M}$ were stained extensively (Figures 1C,D). Trypan blue was applied to indicate cell death in root under $\mathrm{Cd}$ exposure. Root tip treated with $\mathrm{Cd}$ at $16 \mu \mathrm{M}$ showed extensive blue staining as compared to the slight staining of control group and $4 \mu \mathrm{M}$ of Cd treatment (Figure 1E). These results suggested that $\mathrm{Cd}$ at $4 \mu \mathrm{M}$ impeded root elongation without inducing oxidative damage and cell death in the root of B. rapa.

\section{Cd Disturbed ROS Balance in Root Tip}

The location of $\mathrm{H}_{2} \mathrm{O}_{2}$ and $\mathrm{O}_{2}^{\bullet-}$ in root tip were fluorescently detected in vivo by using HPF and DHE, respectively. In normal growth conditions, $\mathrm{H}_{2} \mathrm{O}_{2}$ indicated as green fluorescence mainly distributed in DZ while $\mathrm{O}_{2}^{\bullet-}$ indicated as red fluorescence was located in EZ and meristem zone (MZ) (Figures 2A,B). Compared to the control group, treatment with $\mathrm{Cd}$ at $4 \mu \mathrm{M}$ resulted in significant increase in $\mathrm{H}_{2} \mathrm{O}_{2}$ and remarkable decrease in $\mathrm{O}_{2}^{\bullet-}$ in root tip (Figures $2 \mathbf{C}-\mathbf{F}$ ). To confirm the above results, $\mathrm{H}_{2} \mathrm{O}_{2}$ and $\mathrm{O}_{2}^{\bullet-}$ were also stained with DAB and NBT, respectively. We obtained similar results for the location and Cd-induced changes of $\mathrm{H}_{2} \mathrm{O}_{2}$ and $\mathrm{O}_{2}^{\bullet-}$ as compared to the fluorescently detective methods (Supplementary Figures 2A,B). Then we tested the effect of $\mathrm{Cd}$ at $16 \mu \mathrm{M}$ on ROS balance. The results from histochemical analysis indicated that $\mathrm{Cd}$ at $16 \mu \mathrm{M}$ triggered considerable accumulation of both $\mathrm{H}_{2} \mathrm{O}_{2}$ and $\mathrm{O}_{2}^{\bullet-}$ in root tips (Supplementary Figures 2A,B), which may evidence the oxidative injury and cell death in root tip treated with $16 \mu \mathrm{M}$ of $\mathrm{Cd}$. The measurement of the content of $\mathrm{H}_{2} \mathrm{O}_{2}$ and $\mathrm{O}_{2}^{\bullet-}$ in root tip also showed similar results with histochemical analysis (Supplementary Figures 2C,D).

To further ascertain the responses of ROS in root tips under $\mathrm{Cd}$ exposure, we monitored the changes of $\mathrm{H}_{2} \mathrm{O}_{2}$ and $\mathrm{O}_{2}^{\bullet-}$ in a time-course experiment. Compared to the control group, treatment with $\mathrm{Cd}$ at $4 \mu \mathrm{M}$ led to the significant increase in $\mathrm{H}_{2} \mathrm{O}_{2}$ after $12 \mathrm{~h}$ (Figures 3A,B). In contrast, $\mathrm{O}_{2}^{\bullet-}$ began to decrease remarkably in root tip treated with $4 \mu \mathrm{M}$ of $\mathrm{Cd}$ after
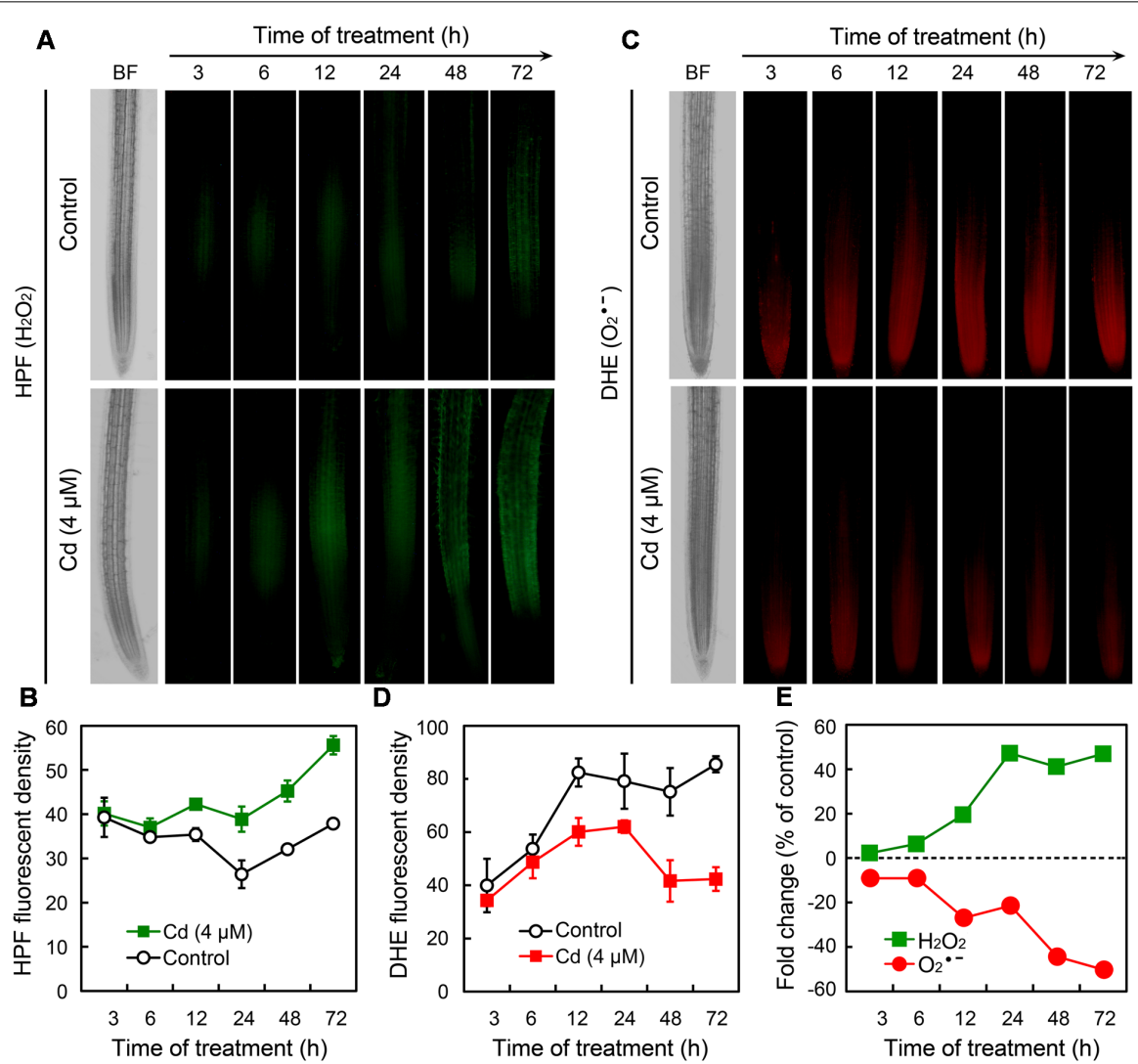

FIGURE 3 | Time-course changes of endogenous $\mathrm{H}_{2} \mathrm{O}_{2}$ and $\mathrm{O}_{2}^{\bullet-}$ in the root tip of $B$. rapa under the treatment of Cd at $4 \mu M$. (A-D) The roots of seedlings were exposed to $\mathrm{O}$ (control) and $4 \mu \mathrm{M}$ of $\mathrm{CdCl}_{2}$ for $3,6,12,24,48$, and $72 \mathrm{~h}$, respectively. Then the roots were loaded with $\mathrm{HPF}$ or DHE to obtain $\mathrm{HPF}$ fluorescent image (A), HPF fluorescent density (B), DHE fluorescent image (C), and DHE fluorescent density (D). (E) CdCl 2 (4 $\mu$ M)-induced fold changes of HPF and DHE fluorescent density in root tip as compared to the control groups. 
$12 \mathrm{~h}$ (Figures 3C,D). The changing patterns of $\mathrm{H}_{2} \mathrm{O}_{2}$ and $\mathrm{O}_{2}^{\bullet-}$ were also indicated by the fold change with respect to control (Figure 3E). These results demonstrated that treatment with $\mathrm{Cd}$ at $4 \mu \mathrm{M}$ disturbed ROS balance by decreasing $\mathrm{O}_{2}^{\bullet-}$ and increasing $\mathrm{H}_{2} \mathrm{O}_{2}$ in the root tip of B. rapa.

\section{The Altered ROS Balance was Closely Linked to the Inhibition of Root Elongation Under $\mathbf{C d}(4 \mu \mathrm{M})$ Exposure}

Since $\mathrm{Cd}$ at $4 \mu \mathrm{M}$ differentially regulated $\mathrm{H}_{2} \mathrm{O}_{2}$ and $\mathrm{O}_{2}^{\bullet-}$ without inducing oxidative injury in root tip, we wondered whether the altered ROS balance was associated with the Cdinduced growth retardation of root. To confirm the role of $\mathrm{O}_{2}^{\bullet-}$ in the positive regulation of root elongation, DPI was applied to inhibit NADPH oxidase that is one of the major source of $\mathrm{O}_{2}^{\bullet-}$ generation in plant cells. Treatment with DPI significantly decreased endogenous $\mathrm{O}_{2}^{\bullet-}$ content in root tips (Figures 4A,B), coinciding with the significant increase in $\mathrm{H}_{2} \mathrm{O}_{2}$ and the ratio of $\mathrm{H}_{2} \mathrm{O}_{2} / \mathrm{O}_{2}^{--}$as well as the remarkable decrease in root elongation (Figures 4C-F). Exogenous application of $\mathrm{H}_{2} \mathrm{O}_{2}$ resulted in considerable increase in endogenous $\mathrm{H}_{2} \mathrm{O}_{2}$ and significant decrease in root elongation, which was similar to the action of treatment with Cd at $4 \mu \mathrm{M}$ (Figures 4G,H). Treatment with $\mathrm{KI}\left(\mathrm{H}_{2} \mathrm{O}_{2}\right.$ scavenger) was able to decrease endogenous $\mathrm{H}_{2} \mathrm{O}_{2}$ content and to promote root elongation in the presence of $\mathrm{Cd}$ $(4 \mu \mathrm{M})$ or not (Figures $\mathbf{4 G}, \mathbf{H})$. Notably, scavenging excessive $\mathrm{H}_{2} \mathrm{O}_{2}$ by $\mathrm{KI}$ led to the recovery of growth phenotype under treatment of Cd at $4 \mu \mathrm{M}$ (Figures 4G,H). These results evidenced that the inhibition of root elongation induced by $\mathrm{Cd}$ at $4 \mu \mathrm{M}$ may result from the decrease in $\mathrm{O}_{2}^{\bullet-}$ and the increase in $\mathrm{H}_{2} \mathrm{O}_{2}$ in root tip.

\section{Endogenous $\mathrm{H}_{2} \mathrm{~S}$ was Involved in the Differential Regulation of $\mathrm{H}_{2} \mathrm{O}_{2}$ and $\mathrm{O}_{2}^{--}$ in Cd-Treated Root}

Specific fluorescent detection of $\mathrm{H}_{2} \mathrm{~S}$ has been suggested as a promising method to localize and quantify $\mathrm{H}_{2} \mathrm{~S}$ precisely in cells because the in-tube assay of $\mathrm{H}_{2} \mathrm{~S}$ content in tissues always leads to unavoidable losses and failure to the cellular compartmentalization of $\mathrm{H}_{2} \mathrm{~S}$ (Hancock and Whiteman, 2016). In the present study, the endogenous $\mathrm{H}_{2} \mathrm{~S}$ in root tip was selectively tracked in vivo by fluorescent probe WSP-1. $\mathrm{H}_{2} \mathrm{~S}$ preferred to accumulate in EZ in root tip (Figure 5A). In a time-course test up to $72 \mathrm{~h}$, treatment with $\mathrm{Cd}$ at $4 \mu \mathrm{M}$ resulted in the continuous increase in endogenous $\mathrm{H}_{2} \mathrm{~S}$ level in root tip as compared to the control group (Figure 5B). In our previous study, the in silico analysis suggested that there were ten $L C D$ orthologues and two DCD orthologues in the genome of B. rapa (Chen et al., 2014). Transcriptional analysis suggested that treatment with $\mathrm{Cd}$ at $4 \mu \mathrm{M}$ induced significant up-regulation of the expression of seven LCDs (Bra037682, Bra036910, Bra036115, Bra036114, Bra020605, Bra014529, and Bra009985) and one DCD (Bra018726) in the root tip of B. rapa. The expression of two LCDs (Bra039708 and Bra004781) and one DCD (Bra025184) were not impacted significantly by treatment with $4 \mu \mathrm{M}$ of

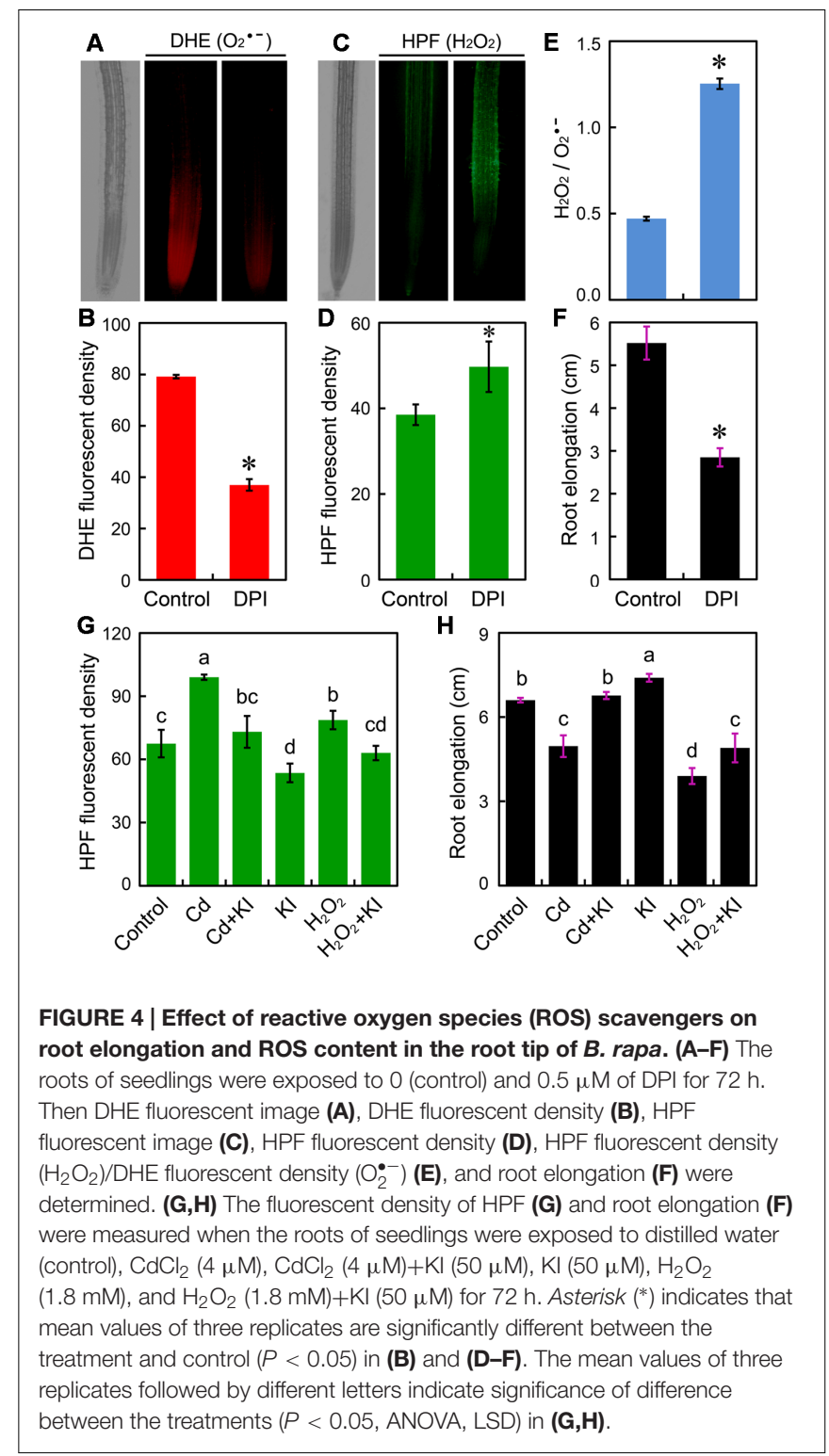

Cd. The expression of only one LCD (Bra001131) was downregulated by treatment with $4 \mu \mathrm{M}$ of $\mathrm{Cd}$ (Figure 5C). These results suggested treatment with $\mathrm{Cd}$ at $4 \mu \mathrm{M}$ stimulated the generation of endogenous $\mathrm{H}_{2} \mathrm{~S}$ in root tip, which may resulted from the extensive up-regulation of $L C D s$ and $D C D s$.

To investigate the possible role of endogenous $\mathrm{H}_{2} \mathrm{~S}$ in the regulation of root growth and ROS balance in Cd-treated root, PAG (endogenous $\mathrm{H}_{2} \mathrm{~S}$ biosynthesis inhibitor) and $\mathrm{HT}\left(\mathrm{H}_{2} \mathrm{~S}\right.$ scavenger) were added to the treatment solution, respectively. The addition of PAG or HT reversed the stimulatory effect of $\mathrm{Cd}(4 \mu \mathrm{M})$ on endogenous $\mathrm{H}_{2} \mathrm{~S}$ (Figure 6A), coinciding with the recovery of root elongation upon $4 \mu \mathrm{M}$ of $\mathrm{Cd}$ (Figure 6B). Intriguingly, the addition of PAG or HT was able to significantly increase the endogenous $\mathrm{O}_{2}^{\bullet-}$ level in root tip under $4 \mu \mathrm{M}$ of Cd treatment with (Figures 6C,D). In addition, PAG or HT remarkably inhibited the increase in endogenous $\mathrm{H}_{2} \mathrm{O}_{2}$ level 

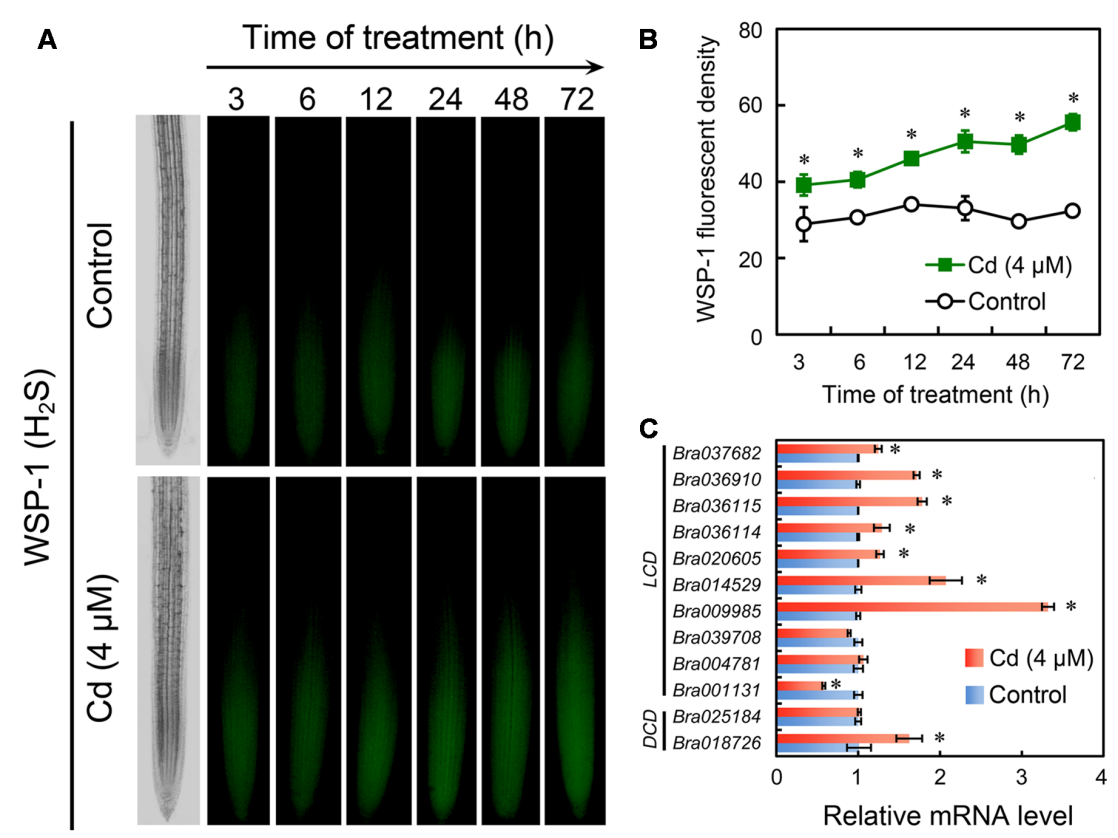

FIGURE 5 | Effect of $\mathrm{Cd}(4 \mu \mathrm{M})$ on the content of endogenous $\mathrm{H}_{2} \mathrm{~S}$ and the expression of $L C D s / D C D s$ in the root tip of $B$. rapa. (A,B) The roots of seedlings were exposed to 0 (control) and $4 \mu \mathrm{M}$ of $\mathrm{CdCl}_{2}$ for $3,6,12,24,48$, and $72 \mathrm{~h}$, respectively. Then the roots were loaded with WSP-1 to obtain WSP-1 fluorescent image (A) and WSP-1 fluorescent density (B). (C) The roots of seedlings were exposed to 0 (control) and $4 \mu \mathrm{M}$ of $\mathrm{CdCl} 2$ for $72 \mathrm{~h}$. Then the root tips were harvested for RNA extraction and real-time PCR analysis for the expression levels of $L C D s$ and DCDs. Actin was used for cDNA normalization. Asterisk indicates that mean values of three replicates are significantly different between treatments and control $(P<0.05)$ in $(\mathbf{B}, \mathbf{C})$.

in $\mathrm{Cd}(4 \mu \mathrm{M})$-treated root tip (Figures $\mathbf{6 E}, \mathbf{F}$ ). These results revealed that the endogenous $\mathrm{H}_{2} \mathrm{~S}$ mediated $\mathrm{Cd}(4 \mu \mathrm{M})$-induced retardation of root elongation by altering the balance between $\mathrm{H}_{2} \mathrm{O}_{2}$ and $\mathrm{O}_{2}^{\bullet-}$ in the root tip of B. rapa.

\section{Endogenous $\mathrm{H}_{2} \mathrm{~S}$ was Involved in the Regulation of $\mathrm{Br}$ UPB1 and Its Downstream Events in Cd-Treated Root}

During the root elongation in Arabidopsis, UPB1 act as a transcriptional factor to repress the expression of several PODs for the further controlling of the balance between $\mathrm{H}_{2} \mathrm{O}_{2}$ and $\mathrm{O}_{2}^{\bullet-}$ (Tsukagoshi et al., 2010). Therefore, we needed to know whether UPB1 could be regulated by Cd. Based on BLAST search against AtUPB1 (At2g47270), two homologues (Bra004465, $\left.B r_{-} U P B 1 A ; B r a 021395, B r_{-} U P B 1 B\right)$ were retrieved from the genome of $B$. rapa. The multi-alignment of deduced amino acid sequences indicated that both Br_UPB1A and Br_UPB1B with conserved bHLH domains shared high similarity with At_UPB1 (Supplementary Figure 3). The expression of both $B r_{-} U P B 1 A$ and $B r_{-} U P B 1 B$ were improved remarkably under the treatment of $\mathrm{Cd}$ at $4 \mu \mathrm{M}$ remarkably as compared to control group, both of which were inhibited by the addition of PAG or HT (Figures 7A,B).

The Arabidopsis bHLH transcript factor family includes two groups, DNA-binders and non-DNA-binders, based on the DNAbinding capacity. At_UPB1 belongs to non-DNA-binder without E-box DNA binding capacity based on the absence of amino acid E41 and/or R44 in the "Basic" domain (Toledo-Ortiz et al., 2003). The similar feature was also found in Br_UPB1A and
Br_UPB1B (Supplementary Figure 3). The mechanism for nonDNA-binding bHLH on the regulation of target genes is still elusive, the ChIP-chip study indicated that At_UPB1 negatively regulated root elongation by directly suppressing the expression of several peroxidase genes (At4g11290, Per39; At4g16270, Per40; At5g17820, Per57) (Tsukagoshi et al., 2010). In the present study, we retrieved the homologues of these Arabidopsis peroxidases from the genome of B. rapa. Bra035235 and Bra033551 were homologues of At4g11290 and At4g16270, respectively. Both Bra023639 and Bra006423 were the homologues of At5g17820 (Supplementary Figures 4 and 5). As expected, the expression of all these four peroxidase genes were inhibited pronouncedly in $\mathrm{Cd}(4 \mu \mathrm{M})$-treated roots compared to the control samples (Figures 7C-F). Notably, the expression of Bra006423 was almost completely suppressed by $\mathrm{Cd}(4 \mu \mathrm{M})$ treatment (Figure $7 \mathrm{E}$ ). As compared to $\mathrm{Cd}$ treatment alone, treatment with $\mathrm{PAG}+\mathrm{Cd}$ or $\mathrm{HT}+\mathrm{Cd}$ significantly enhanced the transcriptional level of Bra035235 and Bra006423 (Figures 7C,E). These results suggested that endogenous $\mathrm{H}_{2} \mathrm{~S}$ up-regulated the expression of $B r_{-} U P B 1$, which may further suppressed the expression of two peroxidase genes (Bra035235 and Bra006423) in Cd (4 $\mu \mathrm{M})$ treated roots.

\section{Hierarchical Cluster Analysis of the Interaction of $\mathrm{H}_{2} \mathrm{~S}$ and ROS in Roots Exposed to Cd}

Based on the obtained data of root length, endogenous $\mathrm{O}_{2}^{\bullet-}$, $\mathrm{H}_{2} \mathrm{O}_{2}, \mathrm{H}_{2} \mathrm{~S}$ content, and the expression of $\mathrm{Br}_{-} U P B 1 A, B r_{-} U P B 1 B$, 
A

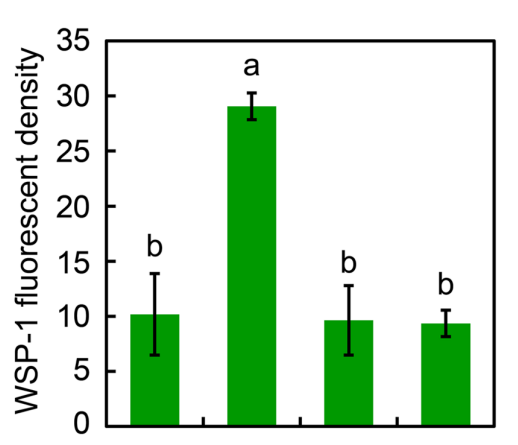

B

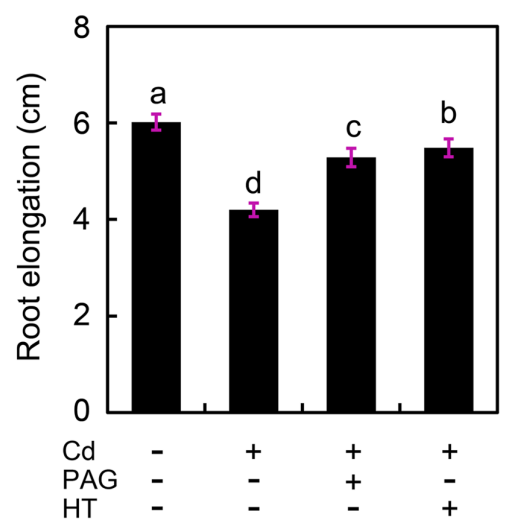

C

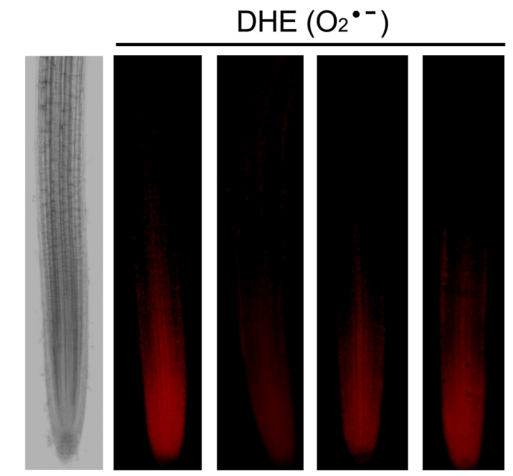

E

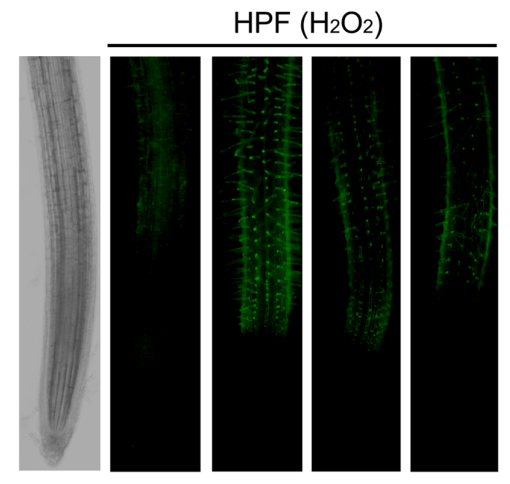

$\mathbf{F}$

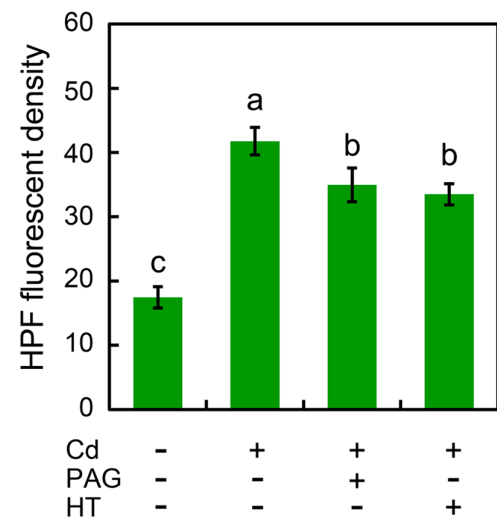

FIGURE 6 | Effect of PAG (DL-propargylglycine) and $\mathrm{HT}$ (hypotaurine) on root elongation as well as the content of endogenous $\mathrm{H}_{2} \mathrm{~S}, \mathrm{H}_{2} \mathrm{O}_{2}$, and $\mathrm{O}_{2}^{\circ-}$ in the root tip of $\boldsymbol{B}$. rapa under treatment of $\mathbf{C d}(\mathbf{4} \mu \mathbf{M})$. The roots of seedlings were exposed to distilled water (control), $\mathrm{CdCl}_{2}(4 \mu \mathrm{M}), \mathrm{CdCl}_{2}(4 \mu \mathrm{M})+\mathrm{PAG}$ $(0.05 \mu \mathrm{M})$, and $\mathrm{CdCl}_{2}(4 \mu \mathrm{M})+\mathrm{HT}(3 \mu \mathrm{M})$ for $72 \mathrm{~h}$. Then the roots were loaded with WSP-1 for the quantification of WSP-1 fluorescent density (A). The root elongation was measured (B). The roots were loaded with DHE to obtain DHE fluorescent image (C) and DHE fluorescent density (D). The roots were loaded with HPF to obtain HPF fluorescent image (E) and HPF fluorescent density $\mathbf{( F )}$. The mean values of three replicates followed by different letters indicate significance of difference between the treatments $(P<0.05$, ANOVA, LSD).

Bra006423, and Bra035235 in roots upon the treatments of different chemicals (Figures 6 and 7), hierarchical clustering was performed to analyze the relationship among biochemical parameters or different treatments (Figure 8). Treatment with endogenous $\mathrm{H}_{2} \mathrm{~S}$ biosynthesis inhibitor (PAG) or $\mathrm{H}_{2} \mathrm{~S}$ scavenger (HT) blocked $\mathrm{Cd}$-induced $\mathrm{H}_{2} \mathrm{~S}$ accumulation, and showed attenuated effects on $\mathrm{Cd}$-induced changes in other parameters (Figure 8), suggesting that $\mathrm{H}_{2} \mathrm{~S}$ mediated Cd-induced phytotoxcity. All the parameters are classified to two groups. $\mathrm{H}_{2} \mathrm{~S}, \mathrm{H}_{2} \mathrm{O}_{2}, B r_{-} U P B 1 A$, and $B r_{-} U P B 1 B$ were stimulated by $\mathrm{Cd}$ treatment, indicating that these parameters contributed to $\mathrm{Cd}$ toxicity. However, the root length, $\mathrm{O}_{2}^{\bullet-}$, Bra006423, and Bra035235 were repressed by $\mathrm{Cd}$ treatment, suggesting that these parameters were negatively regulated by Cd exposure (Figure 8).

\section{DISCUSSION}

$\mathrm{Cd}$ is able to induce the increase in $\mathrm{H}_{2} \mathrm{O}_{2}$ and the decrease in $\mathrm{O}_{2}^{\bullet-}$ in the roots of G. max and C. sativus (Heyno et al., 2008). However, how $\mathrm{Cd}$ differentially regulates $\mathrm{H}_{2} \mathrm{O}_{2}$ and $\mathrm{O}_{2}^{\bullet-}$ in plant cells remains unclear. $\mathrm{H}_{2} \mathrm{~S}$ is an important signaling molecule regulating plant intrinsic physiology (Jin and Pei, 2015). Here we provide evidences that $\mathrm{Cd}$ induces the disturbance between $\mathrm{H}_{2} \mathrm{O}_{2}$ and $\mathrm{O}_{2}^{\bullet-}$ as well as the subsequent growth retard in the roots of $B$. rapa, which is dependent on the expression of $B r_{-} U P B 1$ regulated by endogenous $\mathrm{H}_{2} \mathrm{~S}$.

Cadmium stress frequently induces the accumulation of both $\mathrm{H}_{2} \mathrm{O}_{2}$ and $\mathrm{O}_{2}^{\bullet-}$, leading to the occurrence of oxidative damage (Pérez-Chaca et al., 2014). Here we also found that Cd at relatively high concentration $(16 \mu \mathrm{M})$ resulted in the accumulation of both $\mathrm{H}_{2} \mathrm{O}_{2}$ and $\mathrm{O}_{2}^{\bullet-}$ in the root tip of $B$. rapa, which was confirmed by the subsequent occurrence of oxidative injury and cell death. However, Cd at low concentration $(4 \mu \mathrm{M})$ was able to inhibit root elongation without inducing oxidative injury and cell death, coinciding with the increase in $\mathrm{H}_{2} \mathrm{O}_{2}$ and decrease in $\mathrm{O}_{2}^{\bullet-}$ in root tip. These results promoted us to think about the signaling roles of ROS in the regulation of root growth under Cd stress, rather than the induction of oxidative stress.

Root tip is the important expansion zone responsible for root elongation (Dupuy et al., 2010). In the present study, $\mathrm{H}_{2} \mathrm{O}_{2}$ and $\mathrm{O}_{2}^{\bullet-}$ were detected to be mainly located in $\mathrm{DZ}$ 

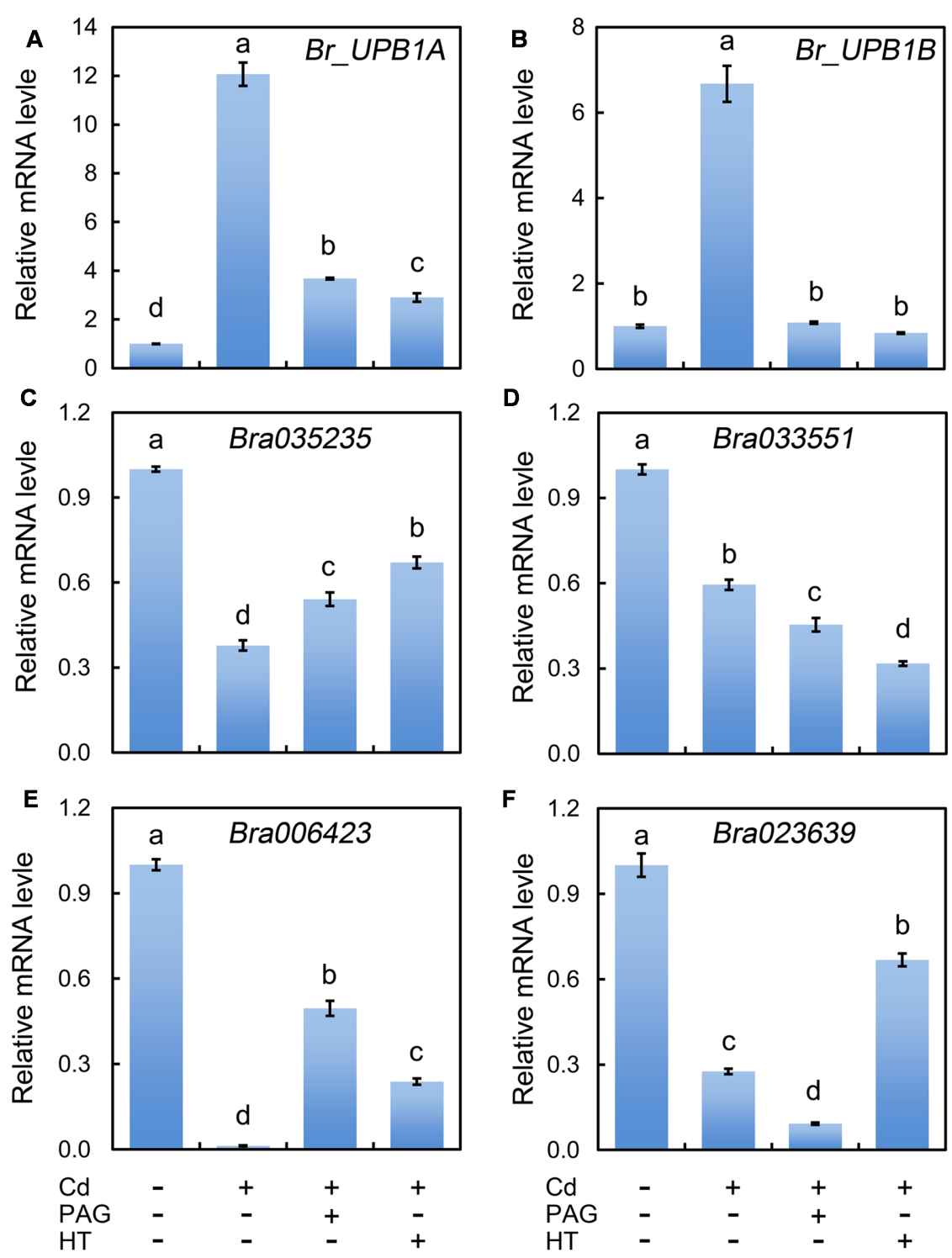

FIGURE 7 | Effect of PAG and HT on the expression of Br_UPB1s and peroxidase genes in the root tip of $\boldsymbol{B}$. rapa under treatment of Cd (4 $\boldsymbol{\mu}$ M). The roots of seedlings were exposed to distilled water (control), $\mathrm{CdCl}_{2}(4 \mu \mathrm{M}), \mathrm{CdCl}_{2}(4 \mu \mathrm{M})+\mathrm{PAG}(0.05 \mu \mathrm{M})$, and $\mathrm{CdCl} 2(4 \mu \mathrm{M})+\mathrm{HT}(3 \mu \mathrm{M})$ for $72 \mathrm{~h}$. Then the root tips were harvested for RNA extraction and real-time PCR analysis of the expression of Br_UPB1s (Br_UPB1A and Br_UPB1B) (A,B) and peroxidase genes (Bra035235, Bra033551, Bra006423, Bra023639) (C-F). Actin was used for cDNA normalization. The mean values of three replicates followed by different letters indicate significance of difference between the treatments $(P<0.05$, ANOVA, LSD).

and $\mathrm{EZ}+\mathrm{MZ}$ of $B$. rapa root tip, respectively, which is similar with the distribution pattern of $\mathrm{H}_{2} \mathrm{O}_{2}$ and $\mathrm{O}_{2}^{\bullet-}$ in the root tip of Arabidopsis (Dunand et al., 2007). Scavenging $\mathrm{H}_{2} \mathrm{O}_{2}$ with KI promoted root elongation of $B$. rapa under $\mathrm{Cd}(4 \mu \mathrm{M})$ treatment or normal conditions, advocating a negative role for $\mathrm{H}_{2} \mathrm{O}_{2}$ in the regulation of root elongation. NADPH oxidase encoded by rbohs (respiratory burst oxidative homologs) has been suggested as a major source for $\mathrm{O}_{2}^{\bullet-}$ generation in plant cells (Suzuki et al., 2011). Treatment with DPI, a NADPH oxidase inhibitor, inhibited $\mathrm{O}_{2}^{\bullet-}$ generation and root elongation, akin to the action of $\mathrm{Cd}(4 \mu \mathrm{M})$ treatment. DPI treatment also stimulated $\mathrm{H}_{2} \mathrm{O}_{2}$ generation in root tip, leading to the increase in the ratio of $\mathrm{H}_{2} \mathrm{O}_{2} / \mathrm{O}_{2}^{\bullet-}$. Thus, it can be speculated that the balance between $\mathrm{H}_{2} \mathrm{O}_{2}$ and $\mathrm{O}_{2}^{\bullet-}$ is vital for root elongation under Cd stress. In addition, DPI treatment may affect other proteins activities besides NADPH oxidase because DPI is a kind of general inhibitor of flavin-containing enzymes but not a specific inhibitor to NADPH oxidase (Bolwell, 1999; Moulton et al., 2000). Therefore, genetic evidences are needed to identify the role of NADPH oxidase-derived $\mathrm{O}_{2}^{\bullet-}$ in the regulation of root elongation upon Cd exposure.

In Arabidopsis, over-expression of UPB1 inhibited root elongation by increasing $\mathrm{H}_{2} \mathrm{O}_{2}$ and decreasing $\mathrm{O}_{2}^{\bullet-}$ in root tip, while the insertional mutation (upb1-1) showed adverse effects 


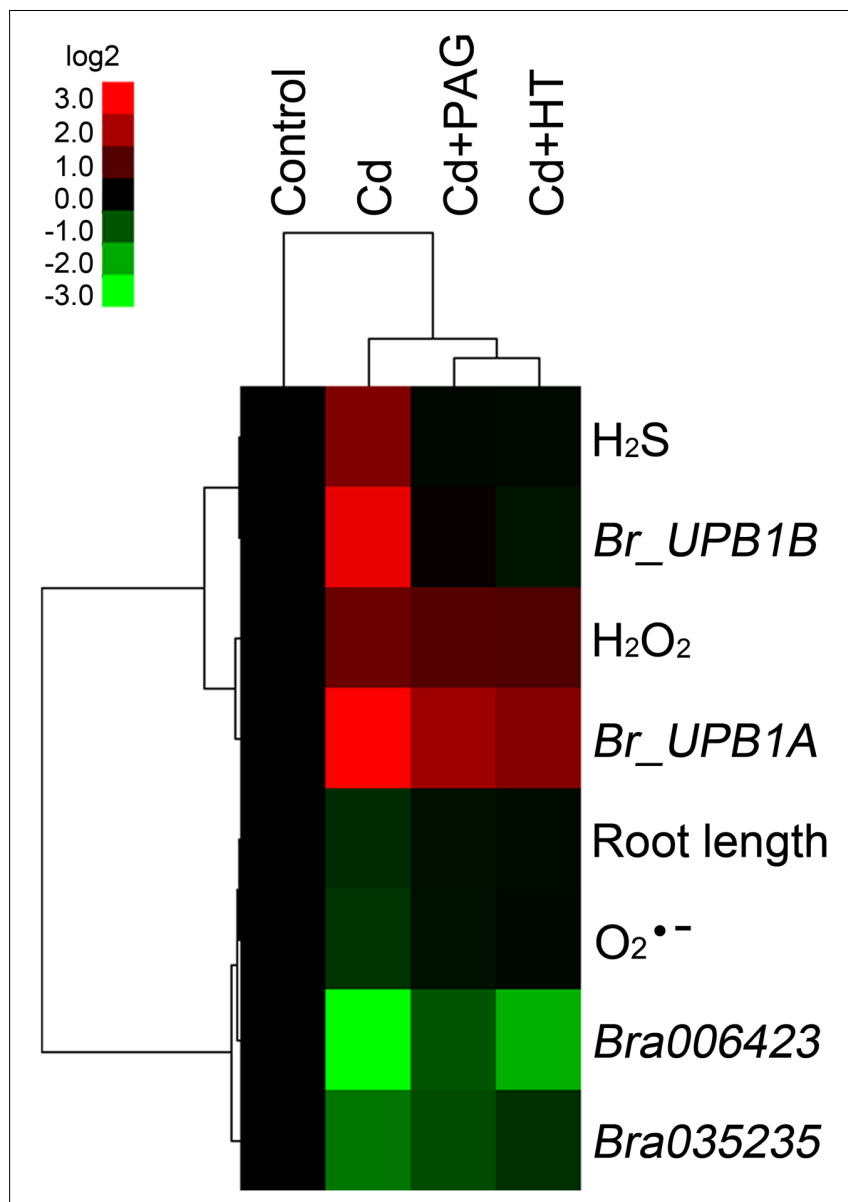

FIGURE 8 | Hierarchical cluster analysis of the effects of PAG and HT on physiological responses of $B$. rapa to $\mathbf{C d}(4 \mu \mathrm{M})$ treatment. The relative data of endogenous $\mathrm{H}_{2} \mathrm{~S}, \mathrm{H}_{2} \mathrm{O}_{2}, \mathrm{O}_{2}^{\bullet-}$ content (presented as specific fluorescent density), root elongation, the expression level of $B r_{-} U P B 1 A$, $\mathrm{Br}$ UPB1B, Bra006423, and Bra035235 in the root tip of $B$. rapa with different treatments, were selected for cluster analysis. All the data were presented as relative fold change respect to the control. The cluster color bar was shown as $\log _{2}$ fold change. The tree was generated by using Cluster 3.0 and Java Treeview as described in Section "Materials and Methods".

(Tsukagoshi et al., 2010). And the balance between $\mathrm{H}_{2} \mathrm{O}_{2}$ and $\mathrm{O}_{2}^{\bullet-}$ maintained by UPB1 seems to regulate root elongation by modulating the onset of cell differentiation but not oxidative injury in root tip. Root cells stop proliferating and start to elongate when the ratio of $\mathrm{O}_{2}^{\bullet-} / \mathrm{H}_{2} \mathrm{O}_{2}$ reaches a proper level (Tsukagoshi et al., 2010). Here we found that Cd $(4 \mu \mathrm{M})$ treatment remarkably up-regulated the expression of two UPB1 homologues ( $B r_{-} U P B 1 A$ and $\left.B r_{-} U P B 1 B\right)$ in the root tip of $B$. rapa, which may explain the downstream observation of ROS alteration and root inhibition without showing oxidative injury. Peroxidase is capable of scavenging $\mathrm{H}_{2} \mathrm{O}_{2}$ by catalyzing $\mathrm{H}_{2} \mathrm{O}_{2}$ to $\mathrm{H}_{2} \mathrm{O}$. In the root tip of Arabidopsis, genetic evidences suggested that UPB1 promoted $\mathrm{H}_{2} \mathrm{O}_{2}$ generation by negatively regulating the expression of several peroxidase genes (Tsukagoshi et al., 2010). In the present study, Cd $(4 \mu \mathrm{M})$ treatment resulted in the down-regulation of four peroxidase gene homologues

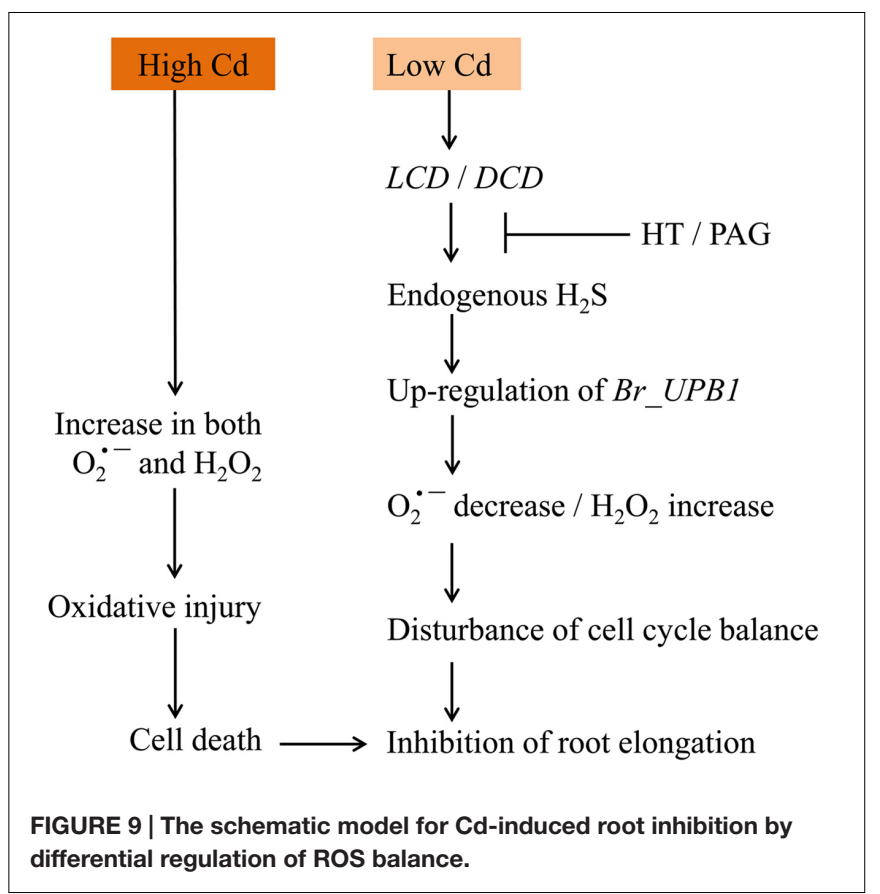

in the root tip of $B$. rapa, leading to the increase in $\mathrm{H}_{2} \mathrm{O}_{2}$. For the decrease in $\mathrm{O}_{2}^{\bullet-}$ observed in this study, one possible reason is the regulation of rbohs. It has been reported that $\mathrm{Cd}$ treatment inhibited NADPH oxidase activity and $\mathrm{O}_{2}^{\bullet-}$ generation in vivo in Helianthus annuus (Groppa et al., 2012). Although the functional redundancy for the maintenance of root meristem may exist among different rboh genes, the loss of $u p b 1$ function mutation resulted in the up-regulation of at least five rbohs in Arabidopsis (Tsukagoshi et al., 2010). Therefore, it is possible that $\mathrm{Cd}(4 \mu \mathrm{M})$ treatment inhibit $\mathrm{O}_{2}^{\bullet-}$ generation by inducing the expression of Br_UPB1s that may further lead to the repression of rbohs. In addition, it has been suggested that $\mathrm{O}_{2}^{\bullet-}$ generation might be driven by the consumption of $\mathrm{H}_{2} \mathrm{O}_{2}$ by peroxidase in Arabidopsis upb1-1 mutant (Tsukagoshi et al., 2010). Our present data demonstrated that $\mathrm{H}_{2} \mathrm{O}_{2}$ generation was promoted by decreasing NADPH oxidase-dependent $\mathrm{O}_{2}^{\bullet-}$ generation in the root tip of $B$. rapa. Therefore, it is interesting to further investigate the mechanism for the modulation between $\mathrm{H}_{2} \mathrm{O}_{2}$ and $\mathrm{O}_{2}^{\bullet-}$ by each other during UPB1-modulated root elongation under $\mathrm{Cd}$ stress or normal growth conditions.

Hydrogen sulfide has been considered as an important node connecting multiple signaling pathways in plants (Jin and Pei, 2015). $\mathrm{H}_{2} \mathrm{~S}$ is able to scavenge ROS by enhancing anti-oxidative capacity in plants under intense environmental stimuli (Hancock and Whiteman, 2015, 2016), but here we found a precise control of the balance between $\mathrm{H}_{2} \mathrm{O}_{2}$ and $\mathrm{O}_{2}^{\bullet-}$ by endogenous $\mathrm{H}_{2} \mathrm{~S}$ in the root tip of $B$. rapa under relatively slighter $\mathrm{Cd}$ stimulus. In our current results, three lines of evidence indicated that Cd $(4 \mu \mathrm{M})$ treatment resulted in Br_UPB1s- modulated ROS balance and root inhibition by triggering endogenous $\mathrm{H}_{2} \mathrm{~S}$ generation in root tip. First, $\mathrm{Cd}(4 \mu \mathrm{M})$ treatment resulted in the increase in endogenous $\mathrm{H}_{2} \mathrm{~S}$ by up-regulating the expression of $L C D s$ and DCD. Second, PAG or HT led to the decrease 
in endogenous $\mathrm{H}_{2} \mathrm{~S}$ level, which further reversed $\mathrm{Cd}(4 \mu \mathrm{M})$ induced changes of the expression level of Br_UPB1s and its two possible target peroxidase genes. Third, the decrease in endogenous $\mathrm{H}_{2} \mathrm{~S}$ by either $\mathrm{PAG}$ or $\mathrm{HT}$ resulted in the recovery from $\mathrm{Cd}(4 \mu \mathrm{M})$-induced ROS balance alteration and root inhibition. LCD/DCD-dependent $\mathrm{H}_{2} \mathrm{~S}$ generation has been found in Medicago sativa, Arabidopsis, and B. rapa under Cd exposure at high concentration (Cui et al., 2014; Qiao et al., 2015, 2016; Zhang et al., 2015). And their reports suggest that $\mathrm{H}_{2} \mathrm{~S}$ acts as a cytoprotectant scavenging Cd-induced overgeneration of $\mathrm{H}_{2} \mathrm{O}_{2}, \mathrm{O}_{2}^{\bullet-}$, and total ROS in plants. However, our present results revealed that LCD/DCD-dependent generation of endogenous $\mathrm{H}_{2} \mathrm{~S}$ disturbed the balance between $\mathrm{H}_{2} \mathrm{O}_{2}$ and $\mathrm{O}_{2}^{\bullet-}$, which further contributed the phytotoxicity induced by $\mathrm{Cd}$ at low concentration. Therefore, it can be proposed that $\mathrm{H}_{2} \mathrm{~S}$ triggers distinct ROS signaling pathways in plant cells in response to different levels of $\mathrm{Cd}$ exposure. In the present study, pharmacological results suggested that endogenous $\mathrm{H}_{2} \mathrm{~S}$ mediated $\mathrm{Cd}(4 \mu \mathrm{M})$-arrested root elongation probably through the stimulation of $B r_{-} U P B 1 s$-regulated cell proliferation in root tip. Intriguingly, tumor-derived endogenous $\mathrm{H}_{2} \mathrm{~S}$ stimulates cell proliferation in colon cancer by regulating Akt kinase and ERK (extracellular signal-regulated kinase) signaling pathways in mammalian cells (Cai et al., 2010; Szabo et al., 2013; Szabo and Hellmich, 2013). Further study on the difference of $\mathrm{H}_{2} \mathrm{~S}$ regulated cell cycle between plants and mammals would help our understanding of the mechanisms for $\mathrm{H}_{2} \mathrm{~S}$ to modulate $\mathrm{Cd}$ adaption in plants.

In addition to $\mathrm{H}_{2} \mathrm{~S}$, NO plays important role in the regulation of root growth. The crosstalk between $\mathrm{H}_{2} \mathrm{~S}$ and $\mathrm{NO}$ has been suggested to be involved in the modulation of plant adaption to Cd stress (Li et al., 2012; Shi et al., 2014) and root development (Zhang et al., 2009; Li et al., 2014). It has been documented that $\mathrm{Cd}$ inhibits meristem growth in the root tip of Arabidopsis. The suppression of Cd-induced NO accumulation compromised Cdinduced root meristem development, indicating that endogenous NO mediates the inhibition of root meristem growth under Cd exposure (Yuan and Huang, 2016). The interaction among $\mathrm{H}_{2} \mathrm{~S}$, NO, and ROS exists extensively in both plants and

\section{REFERENCES}

Andresen, E., and Küpper, H. (2013). “Cadmium toxicity in plants," in Cadmium: From Toxicity to Essentiality, eds A. Sigel, H. Sigel, and R. K. O. Sigel (Dordrecht: Springer Netherlands), 395-413. doi: 10.1007/978-94-007-5179$8 \_13$

Apel, K., and Hirt, H. (2004). Reactive oxygen species: metabolism, oxidative stress, and signal transduction. Annu. Rev. Plant Biol. 55, 373-399.

Bharwana, S. A., Ali, S., Farooq, M. A., Ali, B., Iqbal, N., Abbas, F., et al. (2014). Hydrogen sulfide ameliorates lead-induced morphological, photosynthetic, oxidative damages and biochemical changes in cotton. Environ. Sci. Pollut. Res. Int. 21, 717-731. doi: 10.1007/s11356-013-1920-6

Bhattacharjee, S. (2012). The language of reactive oxygen species signaling in plants. J. Bot. 2012:985298.

Bolwell, G. P. (1999). Role of active oxygen species and NO in plant defence responses. Curr. Opin. Plant Biol. 2, 287-294. doi: 10.1016/S1369-5266(99) 80051-X mammals (Hancock and Whiteman, 2016). Therefore, whether $\mathrm{NO}$ functions in $\mathrm{H}_{2} \mathrm{~S}$-regulated ROS balance in the modulation of Cd-inhibited meristem growth needs to be investigated further.

In sum, a working model was obtained based on our results (Figure 9). Cd exposure at low concentration led to LCDs/DCD-dependent generation of endogenous $\mathrm{H}_{2} \mathrm{~S}$, which further induced the up-regulation of $B r_{-} U P B 1 s$ in root tip. Then the decrease in $\mathrm{O}_{2}^{\bullet-}$ and increase in $\mathrm{H}_{2} \mathrm{O}_{2}$ were triggered, leading to the inhibition of root elongation by probably modulating cell proliferation in root tip. However, $\mathrm{Cd}$ exposure at high concentration directly resulted in the increase in both $\mathrm{H}_{2} \mathrm{O}_{2}$ and $\mathrm{O}_{2}^{\bullet-}$, leading to the occurrence of oxidative injury following by cell death and root growth inhibition. This study not only sheds new light on the regulatory role of $\mathrm{H}_{2} \mathrm{~S}$ in modulating ROS signaling, but also extends our knowledge to understand the mechanism for plant adaptations to Cd stress.

\section{AUTHOR CONTRIBUTIONS}

JC and LY designed the experiments. WL, CX, JS, and ZS performed the experiments. JC and WL analyzed the data. JC and MX contributed to reagents and materials. JC and LY wrote the paper.

\section{FUNDING}

This work was supported by Jiangsu Agriculture Science and Technology Innovation Fund (CX(14)2096 and CX(12)1004) and National Natural Science Foundation of China (31101537 and 21207054).

\section{SUPPLEMENTARY MATERIAL}

The Supplementary Material for this article can be found online at: http://journal.frontiersin.org/article/10.3389/fpls.2017.00232/ full\#supplementary-material

Cai, W.-J., Wang, M.-J., Ju, L.-H., Wang, C., and Zhu, Y.-C. (2010). Hydrogen sulfide induces human colon cancer cell proliferation: role of Akt, ERK and p21. Cell Biol. Int. 34, 565-572. doi: 10.1042/cbi20090368

Chen, J., Wang, W.-H., Wu, F.-H., You, C.-Y., Liu, T.-W., Dong, X.-J., et al. (2013). Hydrogen sulfide alleviates aluminum toxicity in barley seedlings. Plant Soil 362, 301-318. doi: 10.1007/s11104-012-1275-7

Chen, Y., Mo, H. Z., Zheng, M. Y., Xian, M., Qi, Z. Q., Li, Y. Q., et al. (2014). Selenium inhibits root elongation by repressing the generation of endogenous hydrogen sulfide in Brassica rapa. PLoS ONE 9:e110904. doi: 10.1371/journal. pone.0110904

Cui, W., Chen, H., Zhu, K., Jin, Q., Xie, Y., Cui, J., et al. (2014). Cadmium-induced hydrogen sulfide synthesis is involved in cadmium tolerance in Medicago sativa by reestablishment of reduced (Homo)glutathione and reactive oxygen species homeostases. PLoS ONE 9:e109669. doi: 10.1371/journal.pone.0109669

DalCorso, G., Farinati, S., and Furini, A. (2010). Regulatory networks of cadmium stress in plants. Plant Signal. Behav. 5, 663-667.

de Hoon, M. J., Imoto, S., Nolan, J., and Miyano, S. (2004). Open source clustering software. Bioinformatics 20, 1453-1454. doi: 10.1093/bioinformatics/bth078 
Duan, Y., Zhang, W., Li, B., Wang, Y., Li, K., Sodmergen, et al. (2010). An endoplasmic reticulum response pathway mediates programmed cell death of root tip induced by water stress in Arabidopsis. New Phytol. 186, 681-695. doi: $10.1111 / j .1469-8137.2010 .03207 . x$

Dunand, C., Crèvecoeur, M., and Penel, C. (2007). Distribution of superoxide and hydrogen peroxide in Arabidopsis root and their influence on root development: possible interaction with peroxidases. New Phytol. 174, 332-341.

Dupuy, L., Gregory, P. J., and Bengough, A. G. (2010). Root growth models: towards a new generation of continuous approaches. J. Exp. Bot. 61, 2131-2143. doi: 10.1093/jxb/erp389

Fotopoulos, V., Christou, A., Antoniou, C., and Manganaris, G. A. (2015). Hydrogen sulphide: a versatile tool for the regulation of growth and defence responses in horticultural crops. J. Hortic. Sci. Biotechnol. 90, 227-234.

García-Mata, C., and Lamattina, L. (2013). Gasotransmitters are emerging as new guard cell signaling molecules and regulators of leaf gas exchange. Plant Sci. 20, 66-73. doi: $10.1016 /$ j.plantsci.2012.11.007

Gill, S. S., and Tuteja, N. (2010). Reactive oxygen species and antioxidant machinery in abiotic stress tolerance in crop plants. Plant Physiol. Biochem. 48, 909-930. doi: 10.1016/j.plaphy.2010.08.016

Groppa, M. D., Ianuzzo, M. P., Rosales, E. P., Vázquez, S. C., and Benavides, M. P. (2012). Cadmium modulates NADPH oxidase activity and expression in sunflower leaves. Biol. Plant. 56, 167-171. doi: 10.1007/s10535-0120036-z

Hancock, J. T., and Whiteman, M. (2014). Hydrogen sulfide and cell signaling: team player or referee? Plant Physiol. Biochem. 78C, 37-42. doi: 10.1016/j. plaphy.2014.02.012

Hancock, J. T., and Whiteman, M. (2015). "Hydrogen sulfide and reactive friends: the interplay with reactive oxygen species and nitric oxide signalling pathways," in Molecular Physiology and Ecophysiology of Sulfur, eds J. L. De Kok, J. M. Hawkesford, H. Rennenberg, K. Saito, and E. Schnug (Cham: Springer International Publishing), 153-168. doi: 10.1007/978-3-319-20137-5_16

Hancock, J. T., and Whiteman, M. (2016). Hydrogen sulfide signaling: interactions with nitric oxide and reactive oxygen species. Ann. N. Y. Acad. Sci. 1365, 5-14. doi: $10.1111 /$ nyas. 12733

Heyno, E., Klose, C., and Krieger-Liszkay, A. (2008). Origin of cadmium-induced reactive oxygen species production: mitochondrial electron transfer versus plasma membrane NADPH oxidase. New Phytol. 179, 687-699. doi: 10.1111/ j.1469-8137.2008.02512.x

Jakubowska, D., Janicka-Russak, M., Kabała, K., Migocka, M., and Reda, M. (2015). Modification of plasma membrane NADPH oxidase activity in cucumber seedling roots in response to cadmium stress. Plant Sci. 234, 50-59. doi: 10. 1016/j.plantsci.2015.02.005

Jasinski, M., Sudre, D., Schansker, G., Schellenberg, M., Constant, S., Martinoia, E., et al. (2008). AtOSA1, a member of the Abc1-like family, as a new factor in cadmium and oxidative stress response. Plant Physiol. 147, 719-731. doi: 10.1104/pp.107.110247

Jia, H., Hu, Y., Tan, T., and Li, J. (2015). Hydrogen sulfide modulates actindependent auxin transport via regulating ABPs results in changing of root development in Arabidopsis. Sci. Rep. 5:8251. doi: 10.1038/srep08251

Jin, Z., and Pei, Y. (2015). Physiological implications of hydrogen sulfide in plants: pleasant exploration behind its unpleasant odour. Oxid. Med. Cell. Longev. 2015:397502. doi: 10.1155/2015/397502

Ju, Y., Zhang, W., Pei, Y., and Yang, G. (2013). H2S signaling in redox regulation of cellular functions. Can. J. Physiol. Pharmacol. 91, 8-14. doi: 10.1139/cjpp-20120293

Kimura, H. (2011). Hydrogen sulfide: its production, release and functions. Amino Acids 41, 113-121. doi: 10.1007/s00726-010-0510-x

Kimura, H., Shibuya, N., and Kimura, Y. (2012). Hydrogen sulfide is a signaling molecule and a cytoprotectant. Antioxid. Redox Signal. 17, 45-57. doi: 10.1089/ ars.2011.4345

Li, L., Wang, Y., and Shen, W. (2012). Roles of hydrogen sulfide and nitric oxide in the alleviation of cadmium-induced oxidative damage in alfalfa seedling roots. Biometals 25, 617-631. doi: 10.1007/s10534-012-9551-9

Li, Y. J., Chen, J., Xian, M., Zhou, L. G., Han, F. X., Gan, L. J., et al. (2014). In site bioimaging of hydrogen sulfide uncovers its pivotal role in regulating nitric oxide-induced lateral root formation. PLoS ONE 9:e90340. doi: 10.1371/journal. pone. 0090340
Lin, Y. F., and Aarts, M. G. (2012). The molecular mechanism of zinc and cadmium stress response in plants. Cell. Mol. Life Sci. 69, 3187-3206. doi: 10.1007/s00018012-1089-z

Lisjak, M., Teklic, T., Wilson, I. D., Whiteman, M., and Hancock, J. T. (2013). Hydrogen sulfide: environmental factor or signalling molecule? Plant Cell Environ. 36, 1607-1616. doi: 10.1111/pce.12073

Livak, K. J., and Schmittgen, T. D. (2001). Analysis of relative gene expression data using Real-Time Quantitative PCR and the 2- $\Delta \Delta \mathrm{CT}$ method. Methods 25, 402-408. doi: 10.1006/meth.2001.1262

Manzano, C., Pallero-Baena, M., Casimiro, I., De Rybel, B., Orman-Ligeza, B., Van Isterdael, G., et al. (2014). The emerging role of reactive oxygen species signaling during lateral root development. Plant Physiol. 165, 1105-1119. doi: 10.1104/pp.114.238873

Moulton, P., Martin, H., Ainger, A., Cross, A., Hoare, C., Doel, J., et al. (2000). The inhibition of flavoproteins by phenoxaiodonium, a new iodonium analogue. Eur. J. Pharmacol. 401, 115-120. doi: 10.1016/S0014-2999(00)00454-4

Papenbrock, J., Riemenschneider, A., Kamp, A., Schulz-Vogt, H. N., and Schmidt, A. (2007). Characterization of cysteine-degrading and H2S-releasing enzymes of higher plants - from the field to the test tube and back. Plant Biol. 9, 582-588. doi: 10.1055/s-2007-965424

Pérez-Chaca, M. V., RodrÍGuez-Serrano, M., Molina, A. S., Pedranzani, H. E., Zirulnik, F., Sandalio, L. M., et al. (2014). Cadmium induces two waves of reactive oxygen species in Glycine max (L.) roots. Plant Cell Environ. 37, 1672-1687. doi: 10.1111/pce.12280

Qiao, Z., Jing, T., Jin, Z., Liang, Y., Zhang, L., Liu, Z., et al. (2016). CDPKs enhance Cd tolerance through intensifying H2S signal in Arabidopsis thaliana. Plant Soil 398, 99-110. doi: 10.1007/s11104-015-2643-x

Qiao, Z., Jing, T., Liu, Z., Zhang, L., Jin, Z., Liu, D., et al. (2015). H2S acting as a downstream signaling molecule of SA regulates Cd tolerance in Arabidopsis. Plant Soil 393, 137-146. doi: 10.1007/s11104-015-2475-8

Rodríguez-Serrano, M., Romero-Puertas, M. C., Pazmiño, D. M., Testillano, P. S., Risueño, M. C., Del Río, L. A., et al. (2009). Cellular response of pea plants to cadmium toxicity: cross talk between reactive oxygen species, nitric oxide, and calcium. Plant Physiol. 150, 229-243. doi: 10.1104/pp.108.131524

Satarug, S., Garrett, S. H., Sens, M. A., and Sens, D. A. (2010). Cadmium, environmental exposure, and health outcomes. Environ. Health Perspect. 118, 182-190. doi: 10.1289/ehp.0901234

Shi, H., Ye, T., and Chan, Z. (2014). Nitric oxide-activated hydrogen sulfide is essential for cadmium stress response in bermudagrass (Cynodon dactylon $(\mathrm{L})$. Pers.). Plant Physiol. Biochem. 74, 99-107. doi: 10.1016/j.plaphy.2013.11.001

Suzuki, N., Miller, G., Morales, J., Shulaev, V., Torres, M. A., and Mittler, R. (2011). Respiratory burst oxidases: the engines of ROS signaling. Curr. Opin. Plant Biol. 14, 691-699. doi: 10.1016/j.pbi.2011.07.014

Szabo, C., Coletta, C., Chao, C., Modis, K., Szczesny, B., Papapetropoulos, A., et al. (2013). Tumor-derived hydrogen sulfide, produced by cystathionine$\beta$-synthase, stimulates bioenergetics, cell proliferation, and angiogenesis in colon cancer. Proc. Natl. Acad. Sci. U.S.A. 110, 12474-12479. doi: 10.1073/pnas. 1306241110

Szabo, C., and Hellmich, M. R. (2013). Endogenously produced hydrogen sulfide supports tumor cell growth and proliferation. Cell Cycle 12, 2915-2916. doi: $10.4161 / \mathrm{cc} .26064$

Toledo-Ortiz, G., Huq, E., and Quail, P. H. (2003). The Arabidopsis basic/helixloop-helix transcription factor family. Plant Cell 15, 1749-1770.

Tsukagoshi, H., Busch, W., and Benfey, P. N. (2010). Transcriptional regulation of ROS controls transition from proliferation to differentiation in the root. Cell 143, 606-616. doi: 10.1016/j.cell.2010.10.020

Vandiver, M. S., and Snyder, S. (2012). Hydrogen sulfide: a gasotransmitter of clinical relevance. J. Mol. Med. 90, 255-263. doi: 10.1007/s00109-012-0873-4

Wang, R. (2010). Hydrogen sulfide: the third gasotransmitter in biology and medicine. Antioxid. Redox Signal. 12, 1061-1064. doi: 10.1089/ars.2009.2938

Wang, Y. S., and Yang, Z. M. (2005). Nitric oxide reduces aluminum toxicity by preventing oxidative stress in the roots of Cassia tora L. Plant Cell Physiol. 46, 1915-1923. doi: 10.1093/pcp/pci202

Xu, J., Zhu, Y., Ge, Q., Li, Y., Sun, J., Zhang, Y., et al. (2012). Comparative physiological responses of Solanum nigrum and Solanum torvum to cadmium stress. New Phytol. 196, 125-138. doi: 10.1111/j.1469-8137.2012.04236.x

Yamamoto, Y., Kobayashi, Y., Devi, S. R., Rikiishi, S., and Matsumoto, H. (2002), Aluminum toxicity is associated with mitochondrial dysfunction and the 
production of reactive oxygen species in plant cells. Plant Physiol. 128, 63-72. doi: $10.1104 /$ pp.010417

Yamamoto, Y., Kobayashi, Y., and Matsumoto, H. (2001). Lipid peroxidation is an early symptom triggered by aluminum, but not the primary cause of elongation inhibition in pea roots. Plant Physiol. 125, 199-208. doi: 10.1104/pp.125.1.199

Yuan, H.-M., and Huang, X. (2016). Inhibition of root meristem growth by cadmium involves nitric oxide-mediated repression of auxin accumulation and signalling in Arabidopsis. Plant Cell Environ. 39, 120-135. doi: 10.1111/pce. 12597

Zhang, H., Hu, L., Li, P., Hu, K., Jiang, C., and Luo, J. (2010a). Hydrogen sulfide alleviated chromium toxicity in wheat. Biol. Plant. 54, 743-747. doi: 10.1007/ s10535-010-0133-9

Zhang, H., Hu, L.-Y., Hu, K.-D., He, Y.-D., Wang, S.-H., and Luo, J.-P. (2008). Hydrogen sulfide promotes wheat seed germination and alleviates oxidative damage against copper stress. J. Integr. Plant Biol. 50, 1518-1529. doi: 10.1111/ j.1744-7909.2008.00769.x

Zhang, H., Tan, Z.-Q., Hu, L.-Y., Wang, S.-H., Luo, J.-P., and Jones, R. L. (2010b). Hydrogen sulfide alleviates aluminum toxicity in germinating wheat seedlings. J. Integr. Plant Biol. 52, 556-567. doi: 10.1111/j.1744-7909.2010.00946.x

Zhang, H., Tang, J., Liu, X.-P., Wang, Y., Yu, W., Peng, W.-Y., et al. (2009). Hydrogen sulfide promotes root organogenesis in Ipomoea batatas, Salix matsudana and Glycine max. J. Integr. Plant Biol. 51, 1086-1094. doi: 10.1111/j. 1744-7909.2009.00885.x

Zhang, L., Pei, Y., Wang, H., Jin, Z., Liu, Z., Qiao, Z., et al. (2015). Hydrogen sulfide alleviates cadmium-induced cell death through restraining ROS accumulation in roots of Brassica rapa L. ssp. pekinensis. Oxid. Med. Cell. Longev. 2015:804603. doi: $10.1155 / 2015 / 804603$

Conflict of Interest Statement: The authors declare that the research was conducted in the absence of any commercial or financial relationships that could be construed as a potential conflict of interest.

The reviewer JG declared a shared affiliation, though no other collaboration, with one of the authors XM to the handling Editor, who ensured that the process nevertheless met the standards of a fair and objective review.

Copyright $\odot 2017$ Lv, Yang, Xu, Shi, Shao, Xian and Chen. This is an open-access article distributed under the terms of the Creative Commons Attribution License (CC BY). The use, distribution or reproduction in other forums is permitted, provided the original author(s) or licensor are credited and that the original publication in this journal is cited, in accordance with accepted academic practice. No use, distribution or reproduction is permitted which does not comply with these terms. 